\title{
On-Demand Generation and Use in Continuous Synthesis of the Ambiphilic Nitrogen Source Chloramine
}

\author{
Kelley E. Danahy ${ }^{1}$, Evan D. Styduhar ${ }^{1,2}$, Aria M. Fodness ${ }^{1}$, Laurel M. Heckman ${ }^{1,3}$, \\ Timothy F. Jamison*,1 \\ ${ }^{1}$ Department of Chemistry, Massachusetts Institute of Technology, 77 Massachusetts Avenue, Cambridge \\ MA 01239 \\ ${ }^{2}$ Current address: Incyte Research Institute, 1801 Augustine Cut-off, Wilmington DE 19803 \\ ${ }^{3}$ Current address: FM Kirby Neurobiology Research Center, Boston Children's Hospital, 300 Longwood \\ Avenue, Boston, MA 02115 \\ tfj@mit.edu
}




\section{Table of Contents}

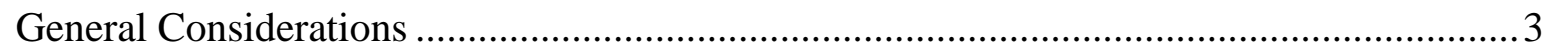

Procedure for Batch Aziridine Synthesis ................................................................ 4

Procedure for Continuous-Flow Aziridine and Nitrile Synthesis .................................5-10

Characterization of Aziridine and Nitrile Products ....................................................11-14

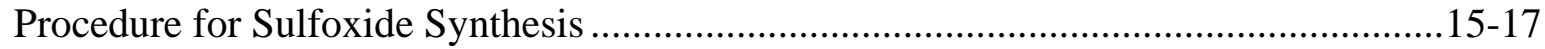

Characterization of Sulfoxide Products..................................................................18-20

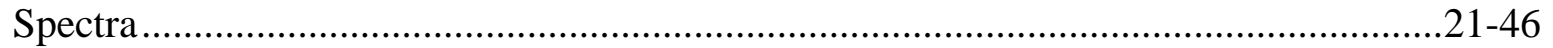




\section{General Considerations}

All reactions were performed with commercial reagents and solvents that were used as received, unless otherwise specified. Reagents and starting materials were purchased from Sigma Aldrich, Alfa Aesar, Combi-Blocks, TCI America, and/or Ark Pharm; solvents were purchased from Fischer or Sigma-Aldrich. Concentration and removal of solvents was performed using a Buchi R-210 rotary evaporator with a dry ice/acetone condenser. Column chromatography was carried out using a prepackaged RediSep High-Performance silica column on a Biotage Isolera One flash chromatography system. Nuclear magnetic resonance (NMR) spectra were recorded on a Bruker $(400 \mathrm{MHz}$ or $500 \mathrm{MHz})$ using chloroform-d $(\mathrm{CDCl} 3)$. Chemical shifts are given in parts per million $(\mathrm{ppm})$ from trimethylsilane $(0.00)$ and measured relative to the solvent signal (1H NMR: $\delta 7.26$ for CDCl3, 13C NMR: $\delta 77.16$ for $\mathrm{CDCl} 3)$. Coupling constants ( $\mathrm{J}$ values) are reported in Hertz $(\mathrm{Hz})$ to the nearest $0.1 \mathrm{~Hz}$. 1H NMR spectra are given in the following order: multiplicity ( $\mathrm{s}$, singlet; $\mathrm{d}$, doublet; $\mathrm{t}$, triplet; m, multiplet), coupling constants, number of protons. 13C NMR spectra are reported in terms of chemical shift (at 100 or $126 \mathrm{MHz}$ ). HRMS was performed using a Jeol AccuTOF LC-plus 4G mass spectrometer equipped with an ESI source. Melting points were obtained using an EZ-Melt automated melting point system manufactured by Stanford Research Systems. Continuous-flow reactions were carried out in high-purity perfluoroalkoxy (HPFA) tubing, purchased from IDEX Health and Science Technologies. Harvard Apparatus syringe pumps were used to continuously deliver reagents, with either Harvard Apparatus stainless steel syringes or SGE Analytical Science glass syringes. Variable back-pressure regulators were purchased from Zaiput Flow Technologies. For in-line extraction, Pall Zefluor PTFE microfiltration membranes $(0.5 \mu \mathrm{m}$ pore size) were placed inside liquid-liquid separators from Zaiput Flow Technologies. For chloramine generation, reservoirs of bleach and an ammonium hydroxide/ammonium chloride solution were pumped through a Vapourtec ESeries Integrated Flow Chemistry System. The concentration of chloramine was then obtained by iodometric titration against a standardized $0.2 \mathrm{M}$ aqueous sodium thiosulfate solution, typically giving concentrations of $0.16-0.18 \mathrm{M}$. 


\section{Procedure for Batch Aziridine Synthesis}

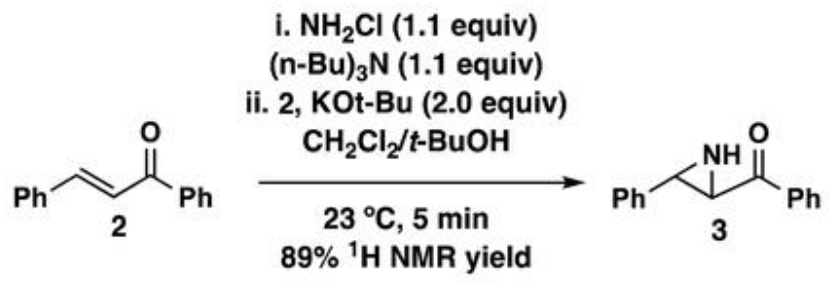

Aziridine 3 To a solution of chloramine prepared in flow as reported in the main text $(0.19$ $\mathrm{M}$ in $\mathrm{CH}_{2} \mathrm{Cl}_{2}, 1 \mathrm{~mL}, 0.19 \mathrm{mmol}, 1.1$ equiv) was added tri- $n$-butylamine (42 $\mu \mathrm{L}, 0.19 \mathrm{mmol}$, 1.1 equiv) and allowed to stir at $23{ }^{\circ} \mathrm{C}$. After $30 \mathrm{~min}$, trans-chalcone $2(0.032 \mathrm{~g}, 0.171 \mathrm{mmol}$, 1.0 equiv) was added, followed by dropwise addition of potassium $t$-butoxide $(1.0 \mathrm{M}$ in $t$ butanol, $285 \mu \mathrm{L}, 0.285 \mathrm{mmol}, 2.0$ equiv) and allowed to stir at $23{ }^{\circ} \mathrm{C}$. After 3 minutes, the reaction was then quenched with a solution of saturated aqueous $\mathrm{NH}_{4} \mathrm{Cl}(2 \mathrm{~mL})$. The resulting biphasic mixture was then transferred to a separatory funnel with $\mathrm{CH}_{2} \mathrm{Cl}_{2}(1 \mathrm{~mL})$ and extracted with $\mathrm{CH}_{2} \mathrm{Cl}_{2}(1 \times 2 \mathrm{~mL})$, followed by extraction with EtOAc $(2 \times 2 \mathrm{~mL})$. The organic layers were combined, dried over $\mathrm{MgSO}_{4}$, and evaporated under reduced pressure, and the yield of $89 \%$ was determined by ${ }^{1} \mathrm{H}$ NMR analysis with 1,3,5- trimethoxybenzene as an external standard. 


\section{Procedure for the Continuous-flow Synthesis of Aziridine 3}

Stock Solution Preparation and Reactor Setup: All solutions were prepared in a chemical fume hood. Stock solution A was obtained directly from a bottle of 10-15\% aqueous sodium hypochlorite, by which the exact concentration of $1.69 \mathrm{M}$ was determined by iodometric titration against a standardized aqueous sodium thiosulfate solution. Based on the concentration of sodium hypochlorite $(1.69 \mathrm{M})$, stock solution $\mathbf{B}$ was prepared by addition of ammonium hydroxide (1.4 equiv with regard to $\mathrm{NaOCl}$ ) and ammonium chloride (1.2 equiv with regard to $\mathrm{NaOCl}$ ) in a dry $250 \mathrm{~mL}$ volumetric flask followed by dilution with $\mathrm{DI} \mathrm{H}_{2} \mathrm{O}$. Stock solution $\mathbf{F}$ was prepared by adding chalcone 2 (6.67 $\mathrm{mmol})$ to a $10-\mathrm{mL}$ volumetric flask followed by dilution with DCM. Stock solutions $\mathbf{C}, \mathbf{E}$, and $\mathbf{G}$ were obtained directly from the reagent bottles.

Procedure: Stock solutions A and B were separately loaded into $100 \mathrm{~mL}$ glass jar reservoirs. Dichloromethane $\mathbf{C}$ was loaded into a $25 \mathrm{~mL}$ SGE glass syringe. Stock solutions $\mathbf{A}$ and $\mathbf{B}$ were pumped from a Vapourtec E-Series Integrated Flow Chemistry System at a rate of $167 \mu \mathrm{L} / \mathrm{min}$ each and combined for a residence time of $1.66 \mathrm{~min}$ in $\mathbf{R} 1$ at $0{ }^{\circ} \mathrm{C}$. Dichloromethane $(\mathbf{C})$ was pumped from a Harvard Apparatus PhD Ultra syringe pump at a rate of $0.5 \mathrm{~mL} / \mathrm{min}$ to combine with the outlet of $\mathbf{R} 1$ at $0{ }^{\circ} \mathrm{C}$ before entering a membrane-based liquid-liquid separator and the resulting solution of chloramine in $\mathrm{CH}_{2} \mathrm{Cl}_{2}$ was collected. The system equilibrated for 15 min prior to collecting into a surge $25 \mathrm{~mL}$ flask. After collecting for an additional $5 \mathrm{~min}$, the concentration of chloramine was then obtained by iodometric titration against a standardized $0.2 \mathrm{M}$ aqueous sodium thiosulfate solution, giving a concentration of 0.17 M. The organic solution $\mathbf{D}$ containing $\mathrm{NH}_{2} \mathrm{Cl}(0.5 \mathrm{~mL} / \mathrm{min}, 0.17 \mathrm{M}, 1.1$ equiv) was then pumped through the system. Flow rates of solutions $\mathbf{E}(1.1$ equiv, $0.1,0.02 \mathrm{~mL} / \mathrm{min}), \mathbf{F}$ $(0.67 \mathrm{M}, 1.0$ equiv, $0.11 \mathrm{~mL} / \mathrm{min})$, and $\mathbf{G}(1.0 \mathrm{M}, 1.5 \mathrm{equiv}, 0.11 \mathrm{~mL} / \mathrm{min})$ were calculated by the concentration of chloramine $\mathbf{D}$ (1.1 equiv). Using the flow rate and concentration of stream $\mathbf{F}$, a collection time was calculated that would correspond to 2 mmol of starting chalcone pumped through the system (26 min 15s). The product stream flowed into an aqueous saturated ammonium chloride solution $(40 \mathrm{~mL})$. When collection was complete, aqueous saturated brine $(20 \mathrm{~mL})$ and DCM $(20 \mathrm{~mL})$ were added. The organic layer was extracted. Next, the aqueous was extracted with EtOAc $(2 \times 30 \mathrm{~mL})$. The crude residue was purified via flash column chromatography on silica gel (0-15\% ethyl acetate in hexanes) to afford the desired aziridine. 


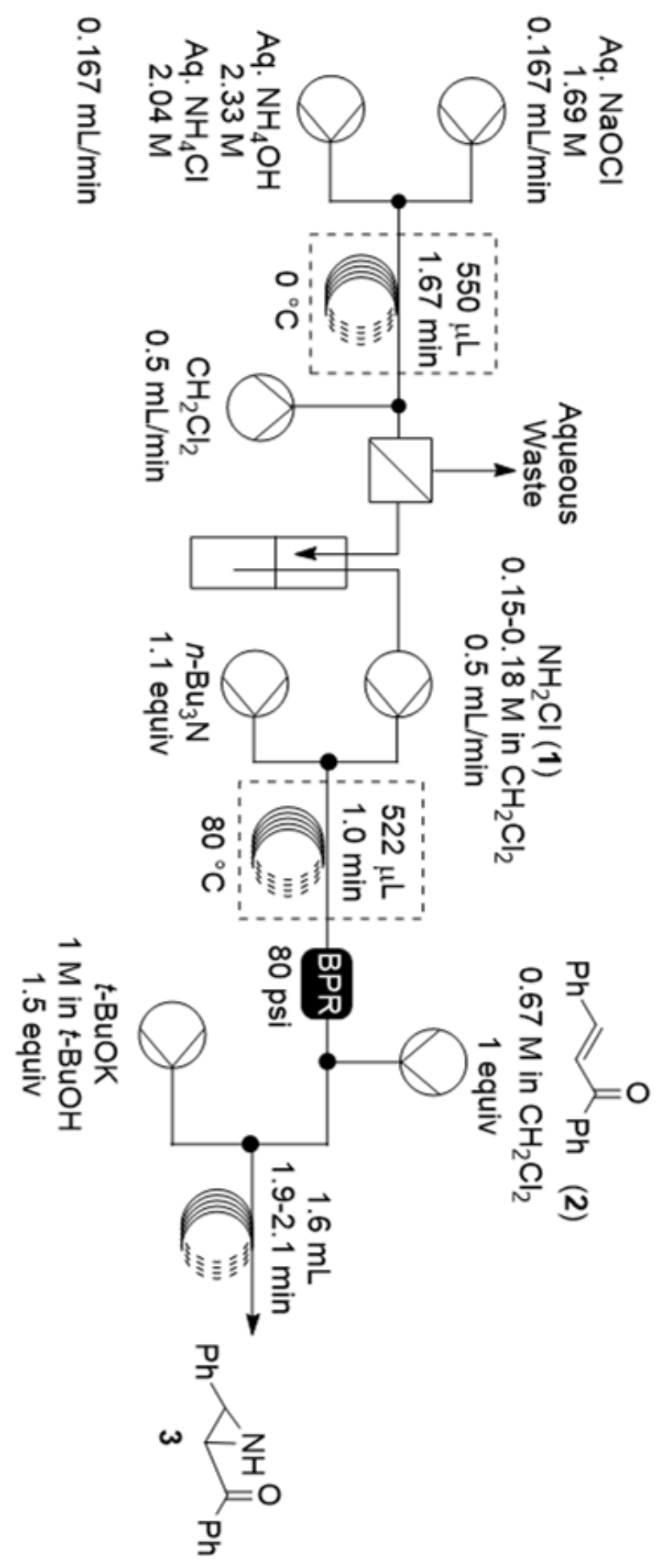

S1. Continuous-flow scheme for aziridine synthesis. 


\section{Procedure for the Continuous-flow Synthesis of Nitriles}

Stock Solution Preparation and Reactor Setup: All solutions were prepared in a chemical fume hood. Stock solution A was obtained directly from a bottle of 10-15\% aqueous sodium hypochlorite, by which the exact concentration was determined by iodometric titration against a standardized aqueous sodium thiosulfate solution. Based on the concentration of sodium hypochlorite, stock solution $\mathbf{B}$ was prepared by addition of ammonium hydroxide (1.39 equiv with regard to $\mathrm{NaOCl}$ ) and ammonium chloride (1.21 equiv with regard to $\mathrm{NaOCl}$ ) in a dry $250 \mathrm{~mL}$ volumetric flask followed by dilution with distilled water. Stock solution $\mathbf{F}$ was prepared by dissolving the desired aldehyde (25 $\mathrm{mmol}$ ) in 5- mL volumetric flask followed by dilution with DCM. Stock solutions $\mathbf{E}$ and G were obtained directly from the reagent bottles.

Procedure: Stock solutions A and B were separately loaded into $100 \mathrm{~mL}$ glass jar reservoirs. Dichloromethane $(\mathbf{C})$ was loaded into a $25 \mathrm{~mL}$ SGE glass syringe. Stock solutions A and B were pumped from a Vapourtec E-Series Integrated Flow Chemistry System at a rate of $167 \mu \mathrm{L} / \mathrm{min}$ each and combined for a residence time of $1.66 \mathrm{~min}$ in $\mathbf{R 1}$ at $0{ }^{\circ} \mathrm{C}$. Dichloromethane $(\mathbf{C})$ was pumped from a Harvard Apparatus PhD Ultra syringe pump at a rate of $500 \mu \mathrm{L} / \mathrm{min}$ to combine with the outlet of $\mathbf{R} 1$ at $0{ }^{\circ} \mathrm{C}$ before entering a membrane-based liquid-liquid separator and the resulting solution of chloramine in $\mathrm{CH}_{2} \mathrm{Cl}_{2}$ was collected. The concentration of chloramine was then obtained by iodometric titration against a standardized $0.2 \mathrm{M}$ aqueous sodium thiosulfate solution, typically giving concentrations of $0.15-0.18 \mathrm{M}$. Flow rates of solutions $\mathbf{E}$ (1.1 equiv), $\mathbf{F}$ ( $0.5 \mathrm{M}, 1.0$ equiv), and $\mathbf{G}(1.0 \mathrm{M}, 2.0$ equiv) were calculated by the concentration of chloramine (1.1 equiv). Using the flow rate and concentration of stream $\mathbf{F}$, a collection time was calculated that would correspond to $2 \mathrm{mmol}$ of starting aldehyde pumped through the system. The product stream flowed into an aqueous saturated ammonium chloride solution $(40 \mathrm{~mL})$. When collection was complete, aqueous saturated brine (20 $\mathrm{mL})$ and DCM (20 mL) were added. The organic layer was extracted. Next, the aqueous was extracted with EtOAc $(2 \times 30 \mathrm{~mL})$. The crude residue was purified via flash column chromatography on silica gel (0-15\% ethyl acetate in hexanes) to afford the desired nitrile.

For 4-nitrobenzaldehyde and 1-methylindole-2-carboxyaldehyde, clogging was observed upon addition of $\mathrm{KO} t$-Bu at the $\mathrm{Y}$-mixer of $\mathbf{R}_{\mathbf{3}}$. Thus, it was replaced with a tube-in-tube reactor and no further clogging was observed. 


\section{Example Procedure for the Continuous-flow Synthesis of Nitrile 5a}

Stock Solution Preparation and Reactor Setup: Stock solution A was obtained directly from a bottle of 10-15\% aqueous sodium hypochlorite, by which the exact concentration of $1.69 \mathrm{M}$ was determined by iodometric titration against a standardized aqueous sodium thiosulfate solution. Based on the concentration of sodium hypochlorite, stock solution $\mathbf{B}$ was prepared by addition of ammonium hydroxide ( $0.583 \mathrm{~mol}$, from aqueous solution) and ammonium chloride $(0.51 \mathrm{~mol}, 27.28 \mathrm{~g})$ in a dry $250 \mathrm{~mL}$ volumetric flask followed by dilution with distilled water to $250 \mathrm{~mL}$ to provide a solution $2.33 \mathrm{M}$ in ammonium hydroxide (1.39 equiv with regard to $\mathrm{NaOCl}$ ) and $2.04 \mathrm{M}$ in ammonium chloride (1.21 equiv with regard to $\mathrm{NaOCl}$ ). A $0.5 \mathrm{M}$ solution of cinnamaldehyde was prepared by dissolving cinnamaldehyde (4a) $(3.15 \mathrm{~mL}, 25 \mathrm{mmol})$ in a $5-\mathrm{mL}$ volumetric flask followed by dilution with DCM to $5 \mathrm{~mL}$.

Procedure: Stock solutions A and B were separately loaded into $100 \mathrm{~mL}$ glass jar reservoirs. Dichloromethane $(\mathbf{C})$ was loaded into a $25 \mathrm{~mL}$ SGE glass syringe. Stock solutions $\mathbf{A}$ and $\mathbf{B}$ were pumped from a Vapourtec E-Series Integrated Flow Chemistry System at a rate of $167 \mu \mathrm{L} / \mathrm{min}$ each and combined for a residence time of $1.66 \mathrm{~min}$ in $\mathbf{R} 1$ at $0{ }^{\circ} \mathrm{C}$. Dichloromethane $(\mathbf{C})$ was pumped from a Harvard Apparatus $\mathrm{PhD}$ Ultra syringe pump at a rate of $500 \mu \mathrm{L} / \mathrm{min}$ to combine with the outlet of $\mathbf{R} \mathbf{1}$ at $0{ }^{\circ} \mathrm{C}$ before entering a membrane-based liquid-liquid separator and the resulting solution of chloramine in $\mathrm{CH}_{2} \mathrm{Cl}_{2}$ was collected in a surge tank. The concentration of chloramine was then obtained by iodometric titration against a standardized $0.2 \mathrm{M}$ aqueous sodium thiosulfate solution, giving a concentration of $0.176 \mathrm{M}$. This chloramine solution was pumped at a rate of $0.5 \mathrm{~mL} / \mathrm{min}(0.088 \mathrm{mmol} / \mathrm{min}, 1.1$ equiv $)$, and $n-\mathrm{Bu}_{3} \mathrm{~N}$ was flowed at $20.9 \mu \mathrm{L} / \mathrm{min}(0.088 \mathrm{mmol} / \mathrm{min}, 1.1$ equiv $)$, and they were combined for a residence time of 1 minute in $\mathbf{R 2}$ at $80{ }^{\circ} \mathrm{C}$. The outlet of $\mathbf{R 2}$ was connected to a BPR set to 80 PSI, which is connected to $\mathbf{R 3}$. Cinnamaldehyde $(0.5 \mathrm{M}$ in DCM) was flowed at $160 \mu \mathrm{L} / \mathrm{min}(0.080$ $\mathrm{mmol} / \mathrm{min}, 1$ equiv wrt chloramine), and $t$-BuOK $(1 \mathrm{M}$ in $t-\mathrm{BuOH})$ was flowed at 160 $\mu \mathrm{L} / \mathrm{min}(0.160 \mathrm{mmol} / \mathrm{min}, 2$ equiv wrt chloramine), into $\mathbf{R 3}$, where they combined for a residence time of 1 minute 54 seconds ( 1.9 minutes) at room temperature. The output of $\mathbf{R 3}$ was then flowed into an aqueous saturated ammonium chloride solution (40 mL) for 25 minutes. The collection time of 25 minutes was calculated based on the time taken to allow $2 \mathrm{mmol}$ of aldehyde to have been reacted and flowed through the system, based on the molar flow rate of cinnamaldehyde of $0.08 \mathrm{mmol} / \mathrm{min}$. When collection was complete, aqueous saturated brine $(20 \mathrm{~mL})$ and DCM $(20 \mathrm{~mL})$ were added. The organic layer was extracted. Next, the aqueous was extracted with EtOAc $(2 \times 30 \mathrm{~mL})$. The crude residue was purified via flash column chromatography on silica gel (0-15\% ethyl acetate in hexanes) to afford cinnamonitrile (5a) in $94 \%$ yield. 


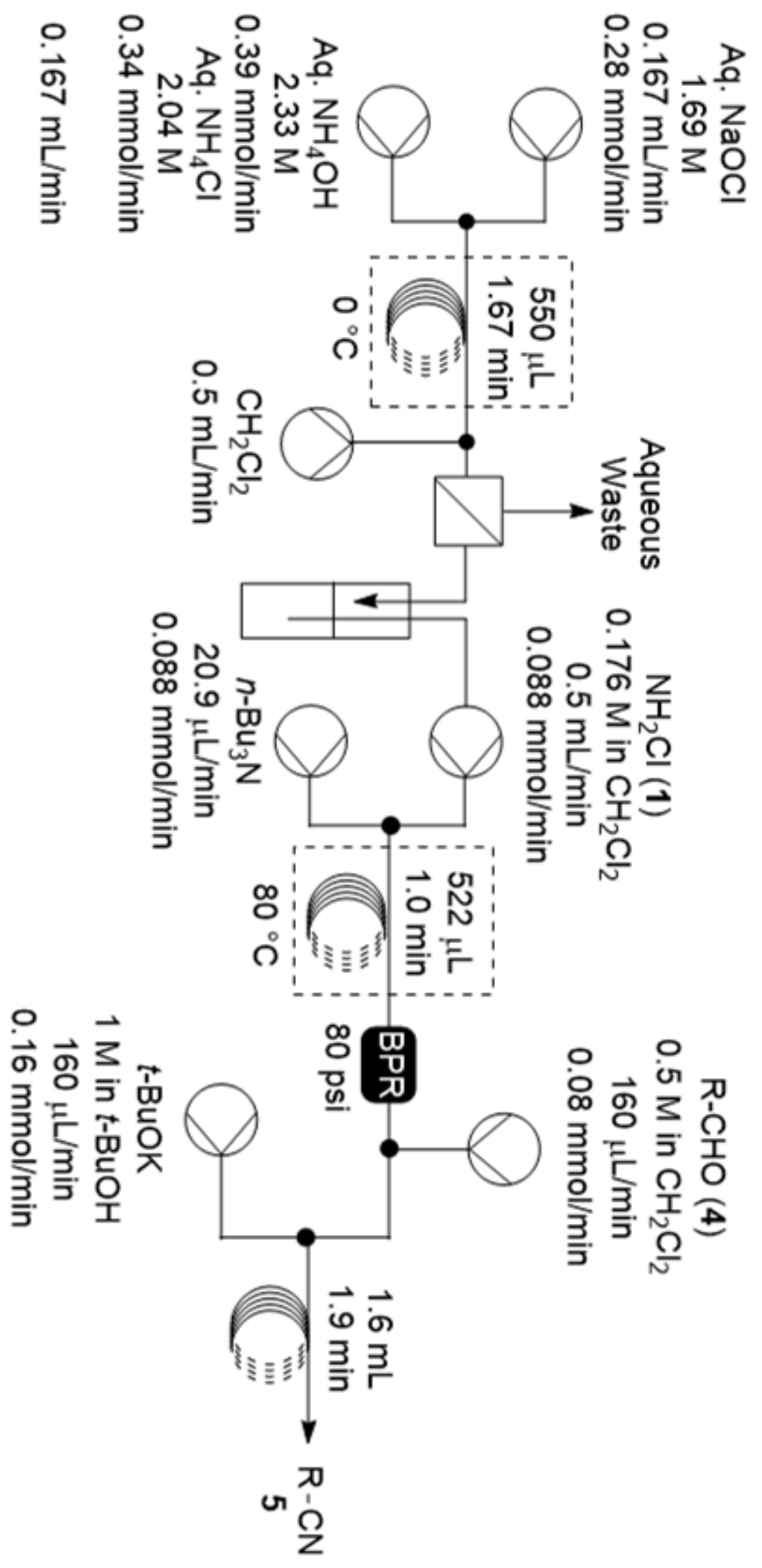

S2. Representative continuous-flow setup for nitrile synthesis. 


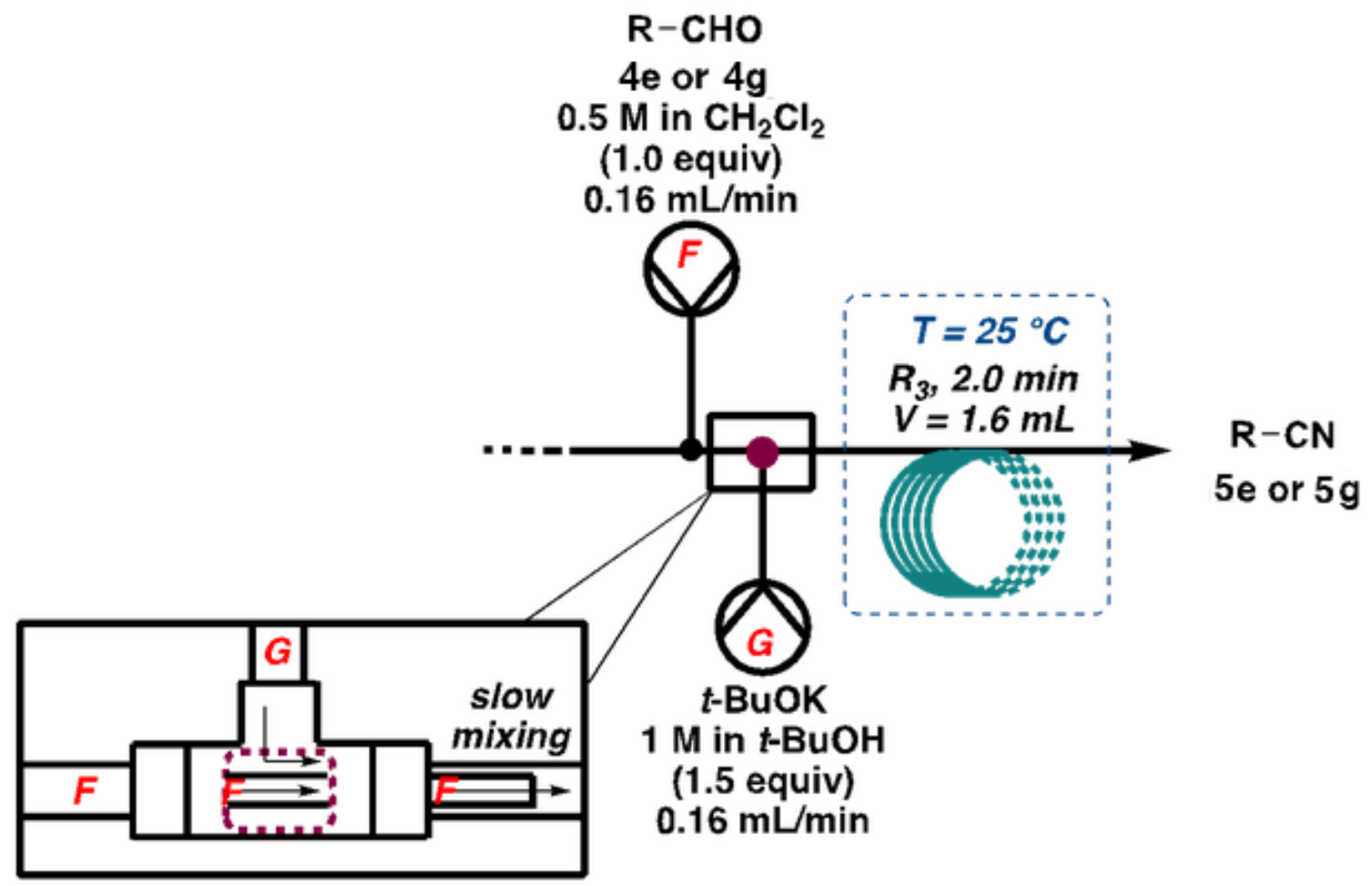

S3. Tube-in-tube mixer for aldehydes $\mathbf{4 e}$ and $\mathbf{4 g}$ prevented clogging. The inner diameter of the outer tube was 0.093 " and the inner diameter of the inner tube was 0.03 ". 


\section{Characterization of Aziridine and Nitrile Products}

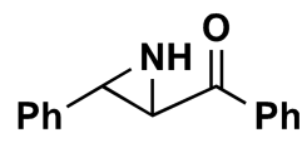

\section{2-Benzoyl-3-Phenylaziridine (3)}

The titled compound was prepared via the previously described procedure for the continuous-flow synthesis of aziridine and purified via flash chromatography on $\mathrm{SiO}_{2}$ (ethyl acetate/hexanes, $0 \% \rightarrow 15 \%$ gradient elution) to yield $\mathbf{3}$ as a white solid (332 $\mathrm{mg}, 1.49 \mathrm{mmol}$, $74 \%$ yield).

${ }^{1}$ H NMR (400 MHz, CDCl3) $\delta 8.03-7.97$ (m, 2H), $7.64-7.58(\mathrm{~m}, 1 \mathrm{H}), 7.52-7.45$ (m, $2 \mathrm{H}), 7.42-7.29(\mathrm{~m}, 5 \mathrm{H}), 3.52(\mathrm{dd}, J=8.0,2.1 \mathrm{~Hz}, 1 \mathrm{H}), 3.19(\mathrm{dd}, J=9.3,2.0 \mathrm{~Hz}, 1 \mathrm{H}), 2.73$ $-2.64(\mathrm{~m}, 1 \mathrm{H}) \mathrm{ppm} ;{ }^{13} \mathbf{C}$ NMR (100 MHz, CDCl3) $\delta$ 195.8, 138.5, 136.0, 133.9, 128.9, 128.6, 128.4, 128.0, 126.3, 44.2, $43.6 \mathrm{ppm}$.

The ${ }^{1} \mathrm{H}$ and ${ }^{13} \mathrm{C}$ NMR spectra are in agreement with those reported in the literature. ${ }^{1}$<smiles>N#C/C=C/c1ccccc1</smiles>

\section{Cinnamonitrile (5a)}

The titled compound was prepared via the previously described example procedure for the continuous-flow synthesis of nitriles and purified via flash chromatography on $\mathrm{SiO}_{2}$ (ethyl acetate/hexanes, $0 \% \rightarrow 15 \%$ gradient elution) to yield $\mathbf{5 a}$ as a colorless oil (243 mg, $1.88 \mathrm{mmol}, 94 \%$ yield).

${ }^{1} \mathbf{H}$ NMR (400 MHz, CDCl3) $\delta 7.51-7.32(\mathrm{~m}, 6 \mathrm{H}), 5.87(\mathrm{~d}, J=16.6 \mathrm{~Hz}, 1 \mathrm{H}) \mathrm{ppm} ;{ }^{13} \mathbf{C}$ NMR (100 MHz, CDCl3) $\delta$ 150.6, 133.5, 131.3, 129.1, 127.4, 118.2, 96.4 ppm.

The ${ }^{1} \mathrm{H}$ and ${ }^{13} \mathrm{C}$ NMR spectra are in agreement with those reported in the literature. ${ }^{2}$<smiles>N#Cc1ccc2ccccc2c1</smiles>

\section{Naphthalene-2-carbonitrile (5b)}

The titled compound was prepared via the previously described procedure for the continuous-flow synthesis of nitriles and purified via flash chromatography on $\mathrm{SiO}_{2}$ (ethyl 
acetate/hexanes, $0 \% \rightarrow 15 \%$ gradient elution) to yield $\mathbf{5 b}$ as a white solid (303 $\mathrm{mg}, 1.98$ mmol, 99\% yield).

${ }^{1}$ H NMR (400 MHz, CDCl $) \delta 8.23(\mathrm{~s}, 1 \mathrm{H}), 7.94-7.86(\mathrm{~m}, 3 \mathrm{H}), 7.70$ - $7.55(\mathrm{~m}, 3 \mathrm{H}) \mathrm{ppm}$; ${ }^{13}$ C NMR (100 MHz, CDCl 3$) \delta$ 134.6, 134.1, 132.2, 129.2, 129.1, 128.4, 128.1, 127.7, 126.3, 119.3, $109.3 \mathrm{ppm}$.

The ${ }^{1} \mathrm{H}$ and ${ }^{13} \mathrm{C}$ NMR spectra are in agreement with those reported in the literature. ${ }^{3}$<smiles>COc1ccc(C#N)cc1</smiles>

\section{4-Methoxybenzonitrile (5c)}

The titled compound was prepared via the previously described procedure for the continuous-flow synthesis of nitriles and purified via flash chromatography on $\mathrm{SiO}_{2}$ (ethyl acetate/hexanes, $0 \% \rightarrow 15 \%$ gradient elution) to yield $\mathbf{5 c}$ as a white solid (239 $\mathrm{mg}, 1.80$ mmol, $90 \%$ yield).

${ }^{1}$ H NMR (400 MHz, CDCl $) \delta 7.61-7.53(\mathrm{~m}, 2 \mathrm{H}), 6.96-6.90(\mathrm{~m}, 2 \mathrm{H}), 3.84(\mathrm{~s}, 3 \mathrm{H}) \mathrm{ppm}$; ${ }^{13}$ C NMR (100 MHz, CDCl3) $\delta$ 162.9, 134.0, 119.3, 114.8, 104.0, 55.6 ppm.

The ${ }^{1} \mathrm{H}$ and ${ }^{13} \mathrm{C}$ NMR spectra are in agreement with those reported in the literature. ${ }^{3}$<smiles>Cc1cccc(C)c1C#N</smiles>

\section{2,6-Dimethylbenzonitrile (5d)}

The titled compound was prepared via the previously described procedure for the continuous-flow synthesis of nitriles and purified via flash chromatography on $\mathrm{SiO}_{2}$ (ethyl acetate/hexanes, $0 \% \rightarrow 15 \%$ gradient elution) to yield $\mathbf{5 d}$ as a white solid (185 $\mathrm{mg}, 1.41$ mmol, $71 \%$ yield).

${ }^{1}$ H NMR (400 MHz, CDCl3) $\delta 7.34(\mathrm{t}, J=7.7 \mathrm{~Hz}, 1 \mathrm{H}), 7.11(\mathrm{~d}, J=7.7 \mathrm{~Hz}, 2 \mathrm{H}), 2.52$ (s, 6H) ppm; ${ }^{13}$ C NMR (100 MHz, CDCl3) $\delta$ 142.2, 132.2, 127.4, 117.4, 113.4, 20.9 ppm.

The ${ }^{1} \mathrm{H}$ and ${ }^{13} \mathrm{C}$ NMR spectra are in agreement with those reported in the literature. ${ }^{4}$<smiles>N#Cc1ccc([N+](=O)[O-])cc1</smiles> 


\section{4-Nitrobenzonitrile (5e)}

The titled compound was prepared via the previously described procedure for the continuous-flow synthesis of nitriles, required a tube-in-tube mixer, and was purified via flash chromatography on $\mathrm{SiO}_{2}$ (ethyl acetate/hexanes, $0 \% \rightarrow 15 \%$ gradient elution) to yield 5e as a white solid (272 $\mathrm{mg}, 1.84 \mathrm{mmol}, 92 \%)$.

${ }^{1}$ H NMR (400 MHz, CDCl3) $\delta 8.35(\mathrm{~d}, J=8.8 \mathrm{~Hz}, 1 \mathrm{H}), 7.89(\mathrm{~d}, J=8.8 \mathrm{~Hz}, 1 \mathrm{H}) \mathrm{ppm} ;{ }^{\mathbf{1 3}} \mathbf{C}$ NMR (100 MHz, CDCl3) $\delta$ 150.1, 133.6, 124.4, 118.4, 116.9 ppm.

The ${ }^{1} \mathrm{H}$ and ${ }^{13} \mathrm{C}$ NMR spectra are in agreement with those reported in the literature. ${ }^{2}$<smiles>N#Cc1csc2ccccc12</smiles>

\section{Benzo[b]thiophene-2-carbonitrile (5f)}

The titled compound was prepared via the previously described procedure for the continuous-flow synthesis of nitriles and purified via flash chromatography on $\mathrm{SiO}_{2}$ (ethyl acetate/hexanes, $0 \% \rightarrow 15 \%$ gradient elution) to yield $\mathbf{5 f}$ as a colorless oil (256 $\mathrm{mg}, 1.61$ mmol, $80 \%$ yield).

${ }^{1} \mathbf{H}$ NMR (400 MHz, CDCl $) \delta 7.96-7.82(\mathrm{~m}, 3 \mathrm{H}), 7.57-7.45(\mathrm{~m}, 2 \mathrm{H}) \mathrm{ppm} ;{ }^{13} \mathbf{C}$ NMR (100 MHz, CDCl $) \delta 141.1,137.3,134.9,127.8,125.6,125.2,122.2,114.4,109.4$ ppm.

The ${ }^{1} \mathrm{H}$ and ${ }^{13} \mathrm{C}$ NMR spectra are in agreement with those reported in the literature. ${ }^{5}$<smiles>Cn1c(C#N)cc2ccccc21</smiles>

\section{1-Methylindole-2-carbonitrile (5g)}

The titled compound was prepared via the previously described procedure for the continuous-flow synthesis of nitriles, required a tube-in-tube mixer, and was purified via flash chromatography on $\mathrm{SiO}_{2}$ (ethyl acetate/hexanes, $0 \% \rightarrow 15 \%$ gradient elution) to yield $\mathbf{5 g}$ as a white solid (284 $\mathrm{mg}, 1.82 \mathrm{mmol}, 91 \%)$.

${ }^{1}$ H NMR (400 MHz, CDCl3) $\delta 7.67(\mathrm{~d}, J=8.1 \mathrm{~Hz}, 1 \mathrm{H}), 7.42(\mathrm{t}, J=7.7 \mathrm{~Hz}, 1 \mathrm{H}), 7.33(\mathrm{~d}$, $J=8.4 \mathrm{~Hz}, 1 \mathrm{H}), 7.23(\mathrm{t}, J=7.5 \mathrm{~Hz}, 1 \mathrm{H}), 7.13(\mathrm{~s}, 1 \mathrm{H}), 3.85(\mathrm{~s}, 3 \mathrm{H}) \mathrm{ppm} ;{ }^{13} \mathbf{C}$ NMR (100 MHz, $\left.\mathbf{C D C l}_{3}\right) \delta 137.9,126.1,125.8,122.3,121.4,113.6,112.6,110.2,110.1,31.4$ ppm.

The ${ }^{1} \mathrm{H}$ and ${ }^{13} \mathrm{C}$ NMR spectra are in agreement with those reported in the literature. ${ }^{3}$ 


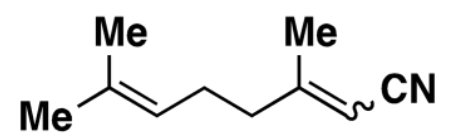

\section{Geranonitrile (5h)}

The titled compound was prepared via the previously described procedure for the continuous-flow synthesis of nitriles and purified via flash chromatography on $\mathrm{SiO}_{2}$ (ethyl acetate/hexanes, $0 \% \rightarrow 15 \%$ gradient elution) to yield $\mathbf{5 h}$ as a colorless oil (217 $\mathrm{mg}, 1.45$ mmol, $73 \%, E / Z=1.2: 1)$.

${ }^{1}$ H NMR (400 MHz, CDCl3) $\delta 5.08(\mathrm{~s}, 3.2 \mathrm{H}), 5.00(\mathrm{t}, J=5.8 \mathrm{~Hz}, 1.2 \mathrm{H}), 2.40(\mathrm{t}, J=7.6$ $\mathrm{Hz}, 2 \mathrm{H}), 2.23-2.09(\mathrm{~m}, 6.8 \mathrm{H}), 2.02(\mathrm{~s}, 3.6 \mathrm{H}), 1.88(\mathrm{~s}, 3 \mathrm{H}), 1.66(\mathrm{~s}, 6.6 \mathrm{H}), 1.59(\mathrm{~d}, J=7.5$ $\mathrm{Hz}, 6.6 \mathrm{H}) \mathrm{ppm} ;{ }^{13} \mathbf{C}$ NMR (100 MHz, CDCl 3$) ~ \delta 165.1,165.0,133.3,133.2,122.3,122.2$, $117.3,117.0,95.9,95.3,38.6,36.3,26.2,25.68,25.67,25.65,22.9,21.0,17.7,17.9$ ppm.

The ${ }^{1} \mathrm{H}$ and ${ }^{13} \mathrm{C}$ NMR spectra are in agreement with those reported in the literature. ${ }^{6}$ 


\section{Procedure for the Continuous-flow Synthesis of Sulfoxides:}

Stock solution preparation: Stock solution A was obtained from a bottle of 10-15\% aqueous sodium hypochlorite, by which the exact concentration was determined by iodometric titration against a standardized aqueous sodium thiosulfate solution. Based on the concentration of sodium hypochlorite, stock solution B was prepared by addition of ammonium hydroxide (1.39 equiv with regard to $\mathrm{NaOCl})$ and ammonium chloride (1.21 equiv with regard to $\mathrm{NaOCl}$ ) in a dry $250 \mathrm{~mL}$ volumetric flask followed by dilution with distilled water. For stock solution $\mathbf{E}$, a $2 \mathrm{~mL}$ volumetric flask was charged with $2 \mathrm{mmol}$ of the desired commercially available thioether, with the exception of $\mathbf{6 c}$, which was obtained as a gift from Dr. Bryan Ingoglia of the Buchwald group and matched previously reported spectra. $^{7}$ Dichloromethane was added to reach a volume of $2 \mathrm{~mL}$. For stock solution $\mathbf{F}, 143$ $\mathrm{mL}(2 \mathrm{mmol})$ of acetyl chloride were dissolved in dichloromethane up to $2 \mathrm{~mL}$ using a volumetric flask.

Procedure: Stock solutions A and B were separately loaded into glass jar reservoirs. Dichloromethane $(\mathbf{C})$ was loaded into a $25 \mathrm{~mL}$ SGE glass syringe. Stock solutions A and B were pumped from a Vapourtec E-Series Integrated Flow Chemistry System at a rate of 167 $\mu \mathrm{L} / \mathrm{min}$ each and combined for a residence time of $1.66 \mathrm{~min}$ in $\mathbf{R} \mathbf{1}$ at $0{ }^{\circ} \mathrm{C}$. Dichloromethane (C) was pumped from a Harvard Apparatus PhD Ultra syringe pump at a rate of $500 \mu \mathrm{L} / \mathrm{min}$ to combine with the outlet of $\mathbf{R} \mathbf{1}$ at $0{ }^{\circ} \mathrm{C}$ before entering a membrane-based liquid-liquid separator. The resulting solution of chloramine in $\mathrm{CH}_{2} \mathrm{Cl}_{2}$ was collected. The concentration of chloramine was then obtained by iodometric titration against a standardized $0.2 \mathrm{M}$ aqueous sodium thiosulfate solution, typically giving concentrations of $0.15-0.18 \mathrm{M}$. Flow rates of solutions $\mathbf{E}$ (1 M, 1 equiv) and $\mathbf{F}$ (1 M, 1 equiv) were calculated by the concentration 
of chloramine ( 2 equiv). A collection time was calculated that would correspond to $1 \mathrm{mmol}$ of starting thioether pumped into the system. Before collection, ten seconds were allowed to pass for equilibration. The heterogeneous product stream flowed into an Erlenmeyer flask filled with methanol as a mild quench $(10 \mathrm{~mL})$.

The solution was evaporated on a rotary evaporator, and the sulfoxide re-suspended in dichloromethane. The suspension was transferred to a separatory funnel, and washed with saturated aqueous sodium bicarbonate. The organic layer was dried over sodium sulfate, filtered, and the dichloromethane evaporated. The crude sulfoxide was then purified via column chromatography with ethyl acetate and hexanes, using a RediSep High-Performance silica column on a Biotage Isolera One flash chromatography system. 


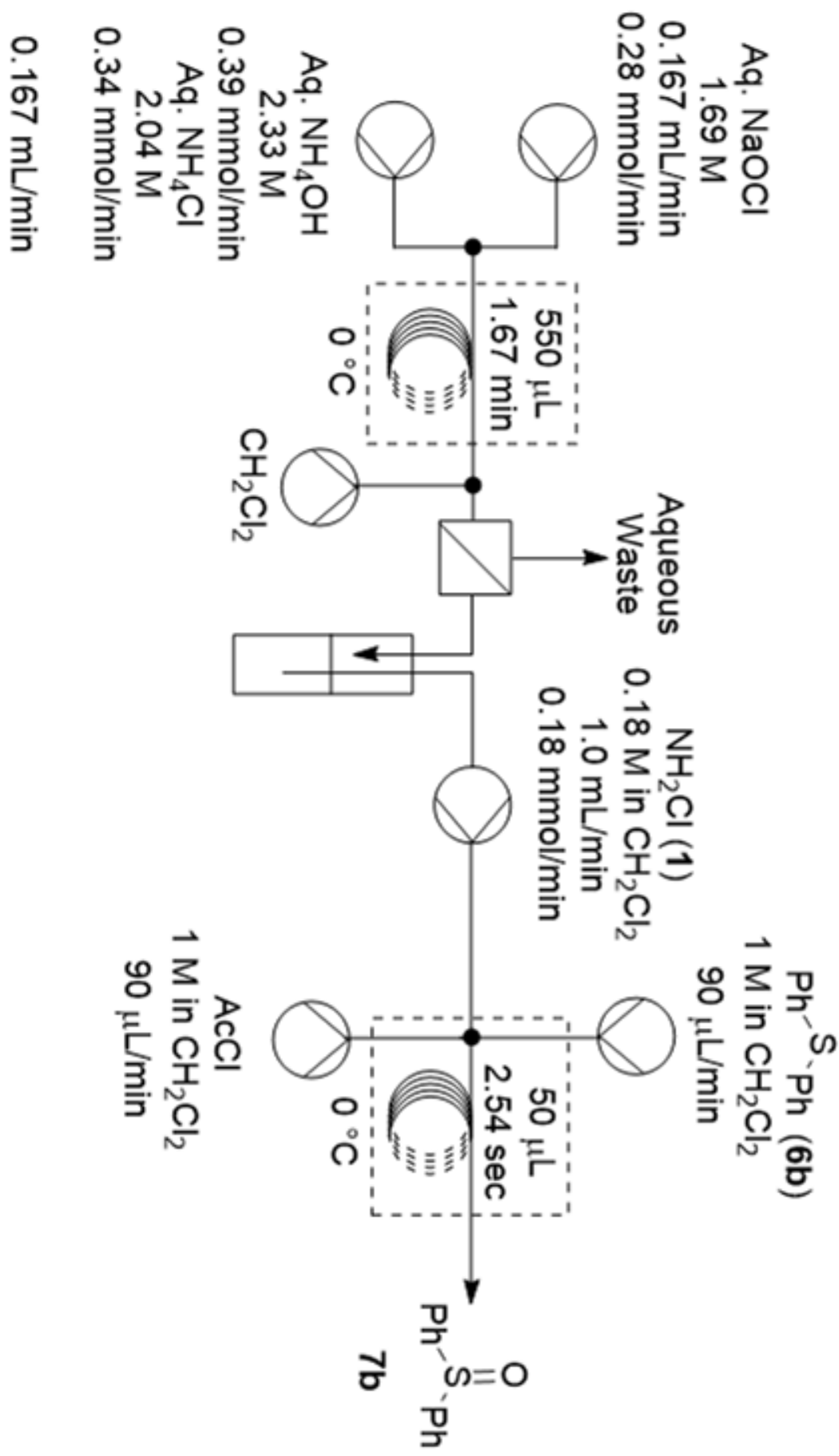

S4. Representative continuous-flow setup for sulfoxide synthesis 
<smiles>CS(=O)c1ccccc1</smiles>

(Methylsulfinyl)benzene (7a): The titled compound was prepared via the previously described procedure for the continuous-flow synthesis of sulfoxides and was purified via flash chromatography on $\mathrm{SiO}_{2}$ (ethyl acetate/hexanes, $25 \% \rightarrow 100 \%$ gradient elution) to yield 7a as a yellow oil (90 mg, $0.64 \mathrm{mmol}, 64 \%$ yield).

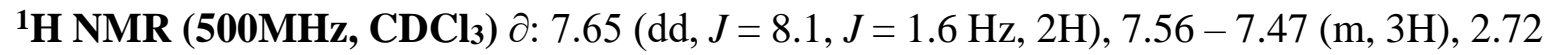
(s, 3H); ${ }^{13} \mathbf{C}$ NMR (126 MHz, CDCl 3$)$ o: 131.2, 129.5, 123.6, 44.1.

The ${ }^{1} \mathrm{H}$ and ${ }^{13} \mathrm{C}$ NMR spectra are in agreement with those reported in the literature. ${ }^{8}$<smiles>O=S(c1ccccc1)c1ccccc1</smiles>

Sulfinyldibenzene (7b): $62 \%$, The titled compound was prepared via the previously described procedure for the continuous-flow synthesis of sulfoxides and was purified via flash chromatography on $\mathrm{SiO}_{2}$ (ethyl acetate/hexanes, $25 \% \rightarrow 100 \%$ gradient elution) to yield $7 \mathbf{b}$ as an off-white solid (126 mg, $0.62 \mathrm{mmol}, 62 \%$ yield).

${ }^{1} \mathbf{H}$ NMR (500MHz, CDCl $\left.\mathbf{3}\right) \partial: 7.65(\mathrm{dd}, J=7.9, J=1.7 \mathrm{~Hz}, 1 \mathrm{H}), 7.51-7.39(\mathrm{~m}, 2 \mathrm{H}) ;{ }^{13} \mathbf{C}$ NMR (126 MHz, CDCl $)$ ) 2 : 131.2, 129.5, 124.9.

The ${ }^{1} \mathrm{H}$ and ${ }^{13} \mathrm{C}$ NMR spectra are in agreement with those reported in the literature. ${ }^{9}$<smiles>CC(C)(C)OS(=O)c1ccccc1S(=O)(=O)O</smiles>

tert-Butyl 10H-phenothiazine-10-carboxylate 5-oxide (7c): The titled compound was prepared via the previously described procedure for the continuous-flow synthesis of sulfoxides and was purified via flash chromatography on $\mathrm{SiO}_{2}$ (ethyl acetate/hexanes, $15 \% \rightarrow 100 \%$ gradient elution) to yield $7 \mathrm{c}$ as an off-white solid (145 mg, $0.46 \mathrm{mmol}, 46 \%)$ with a melting point of $162.7-163.9^{\circ} \mathrm{C}$.

${ }^{1}$ H NMR (400MHz, CDCl3) $\partial: 7.84(\mathrm{dd}, J=7.6, J=1.7 \mathrm{~Hz}, 2 \mathrm{H}), 7.74(\mathrm{dd}, J=7.9,1.3 \mathrm{~Hz}$, 2H), 7.46 (ddd, $J=14.8, J=7.7, J=1.5 \mathrm{~Hz}, 4 \mathrm{H}), 1.54(\mathrm{~s}, 9 \mathrm{H}) ;{ }^{13} \mathrm{C}$ NMR (126 MHz, CDCl$\left._{3}\right) \partial: 151.5,138.8,133.5,130.2,126.9,126.4,124.2,83.6,28.3$; HRMS (ESI-TOF) $[\mathrm{M}+\mathrm{H}]^{+} \mathrm{m} / \mathrm{z}$ : Calcd for $\left(\mathrm{C}_{17} \mathrm{H}_{17} \mathrm{NO}_{3} \mathrm{~S}\right)$ 316.1002; Found 316.1019.

The ${ }^{1} \mathrm{H}$ and ${ }^{13} \mathrm{C}$ NMR spectra are in agreement with those reported in the literature. ${ }^{10}$ 


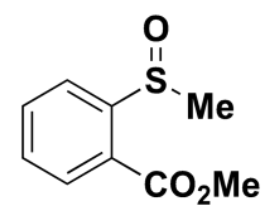

Methyl 2-(methylsulfinyl)benzoate (7d): The titled compound was prepared via the previously described procedure for the continuous-flow synthesis of sulfoxides and was purified via flash chromatography on $\mathrm{SiO}_{2}$ (ethyl acetate/hexanes, $25 \% \rightarrow 100 \%$ gradient elution) to yield $7 \mathbf{d}$ as a clear oil $(73 \mathrm{mg}, 0.37 \mathrm{mmol}, 37 \%)$. Mass balance was a mixture of products resulting from reaction between the preformed sulfilimines and the adjacent methyl ester.

${ }^{1} \mathbf{H}$ NMR (400MHz, CDCl 3$)$ d: $8.32(\mathrm{dd}, J=8.0 \mathrm{~Hz}, J=1.2 \mathrm{~Hz}, 1 \mathrm{H}), 8.09$ (dd, $J=7.7 \mathrm{~Hz}, J$ $=1.3 \mathrm{~Hz}, 1 \mathrm{H}), 7.83(\mathrm{~d}, J=1.3 \mathrm{~Hz}, 1 \mathrm{H}), 7.58(\mathrm{dd}, J=7.5 \mathrm{~Hz}, J=1.3 \mathrm{~Hz}, 1 \mathrm{H}), 3.95(\mathrm{~s}, 3 \mathrm{H})$, 2.85 (s, 3H); $\left.{ }^{13} \mathbf{C ~ N M R ~ ( 1 2 5 M H z , ~} \mathbf{C D C l}_{3}\right) \partial$ : 165.9, 150.6, 134.3, 130.9, 130.3, 126.6, 124.3, $52.8,44.2$.

The ${ }^{1} \mathrm{H}$ and ${ }^{13} \mathrm{C}$ NMR spectra are in agreement with those reported in the literature. ${ }^{11}$ 


\section{References}

1. Shen, Y. M.; Zhao, M. X.; Xu, J.; Shi, Y. Angew. Chem. Int. Ed. Engl. 2006, 45, 8005.

2. Kim, J.; Choi, J.; Shin, K.; Chang, S. J. Am. Chem. Soc. 2012, 134, 2528.

3. Chatupheeraphat, A.; Liao, H.-H.; Lee, S.-C.; Rueping, M. Org. Lett. 2017, 19, 4255.

4. Senecal Todd, D.; Shu, W.; Buchwald Stephen, L. Angew. Chem. Int. Ed. Engl. 2013, 52, 10035.

5. Zhou, W.; Chen, W.; Wang, L. Org. Biomol. Chem. 2012, 10, 4172.

6. An, X.-D.; Yu, S. Org. Lett. 2015, 17, 5064.

7. Darvesh, S.; Darvesh, K. V.; McDonald, R. S.; Mataija, D.; Walsh, R.; Mothana, S.; Lockridge, O.; Martin, E. J. Med. Chem. 2008, 51, 4200.

8. Yuan, Y.; Shi, X.; Liu, W. Synlett. 2011, 559.

9. Jiang, J.; Luo, R.; Zhou, X.; Cheng, Y.; Ji, H. Adv. Synth. Catal. 2018, 360, 4402.

10. Clarke, A.K.; Parkin, A.; Taylor, R.J.K.; Unsworth, W.P.; Rossi-Ashton, J.A. ACS Catal. 2020, 10, 5814.

11. Dai, W.; Li, G.; Wang, L.; Chen, B.; Shang, S.; Lv, Y.; Gao, S. RSC Adv. 2014, 4, 46545. 


\section{$\underline{{ }^{1} \mathrm{H} \text { and }{ }^{13} \mathrm{C} \text { Spectra }}$}

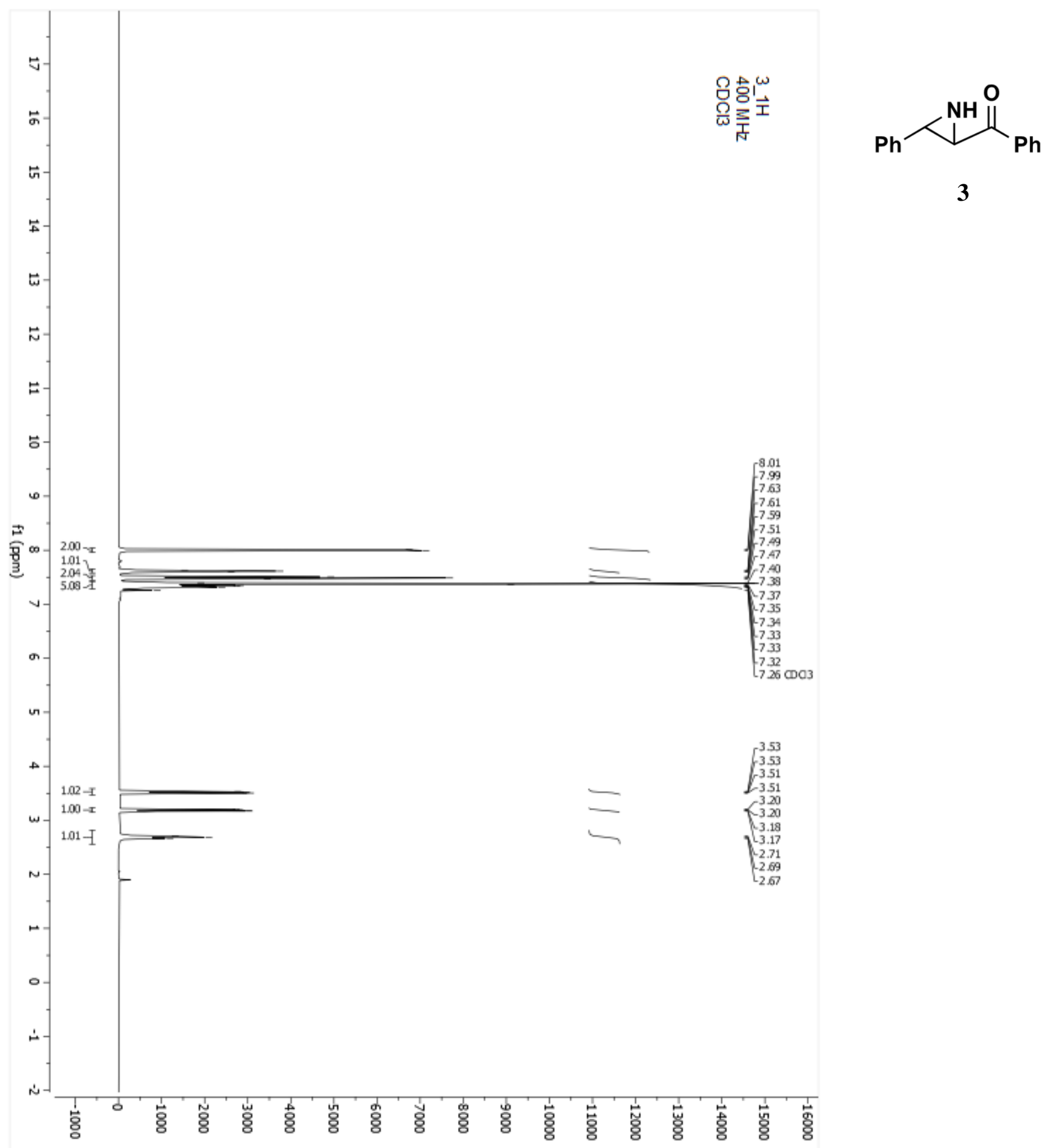

S5. ${ }^{1} \mathrm{H}$ NMR spectrum of 3 . 


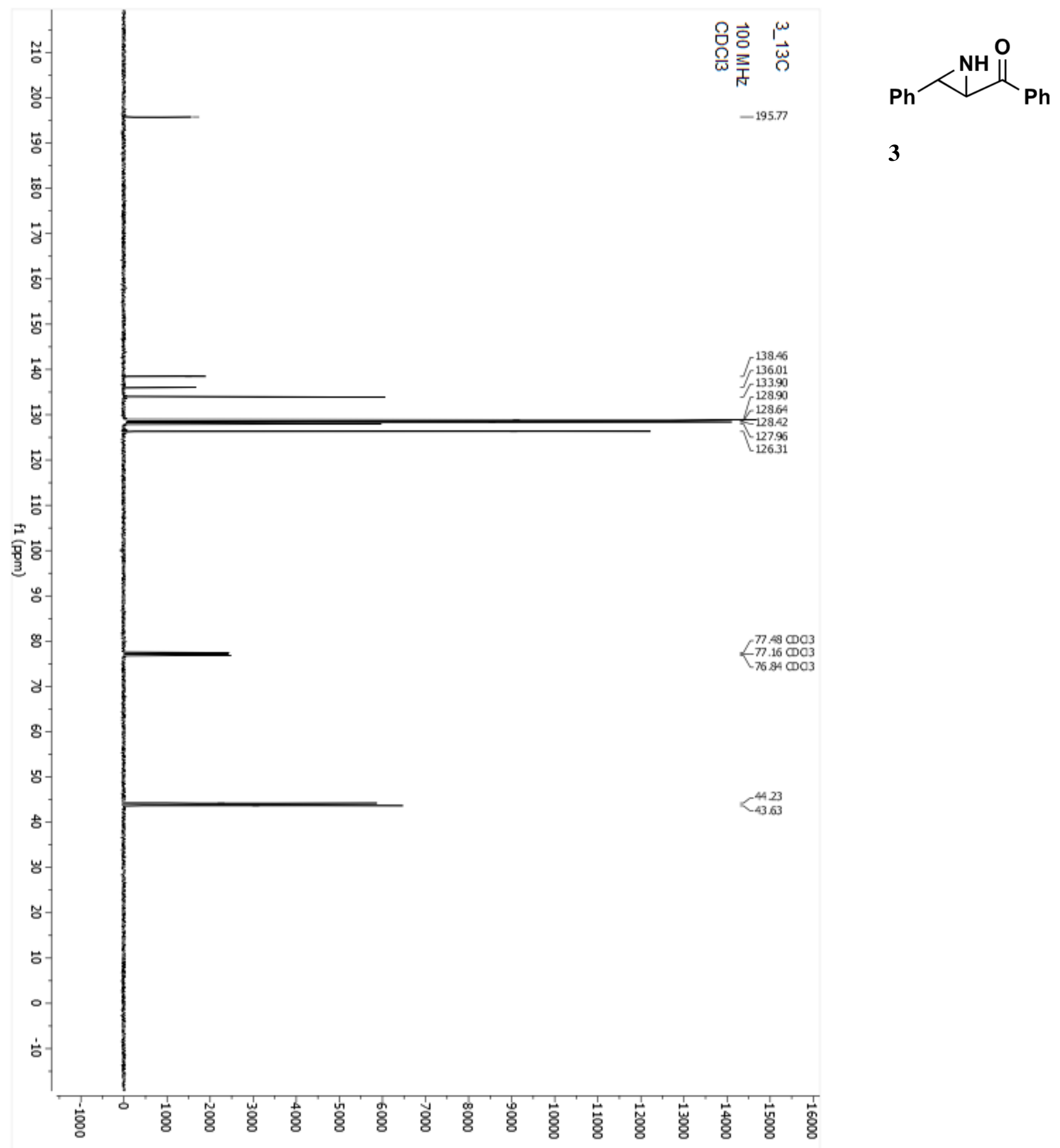

S6. ${ }^{13} \mathrm{C}$ NMR spectrum of $\mathbf{3}$. 


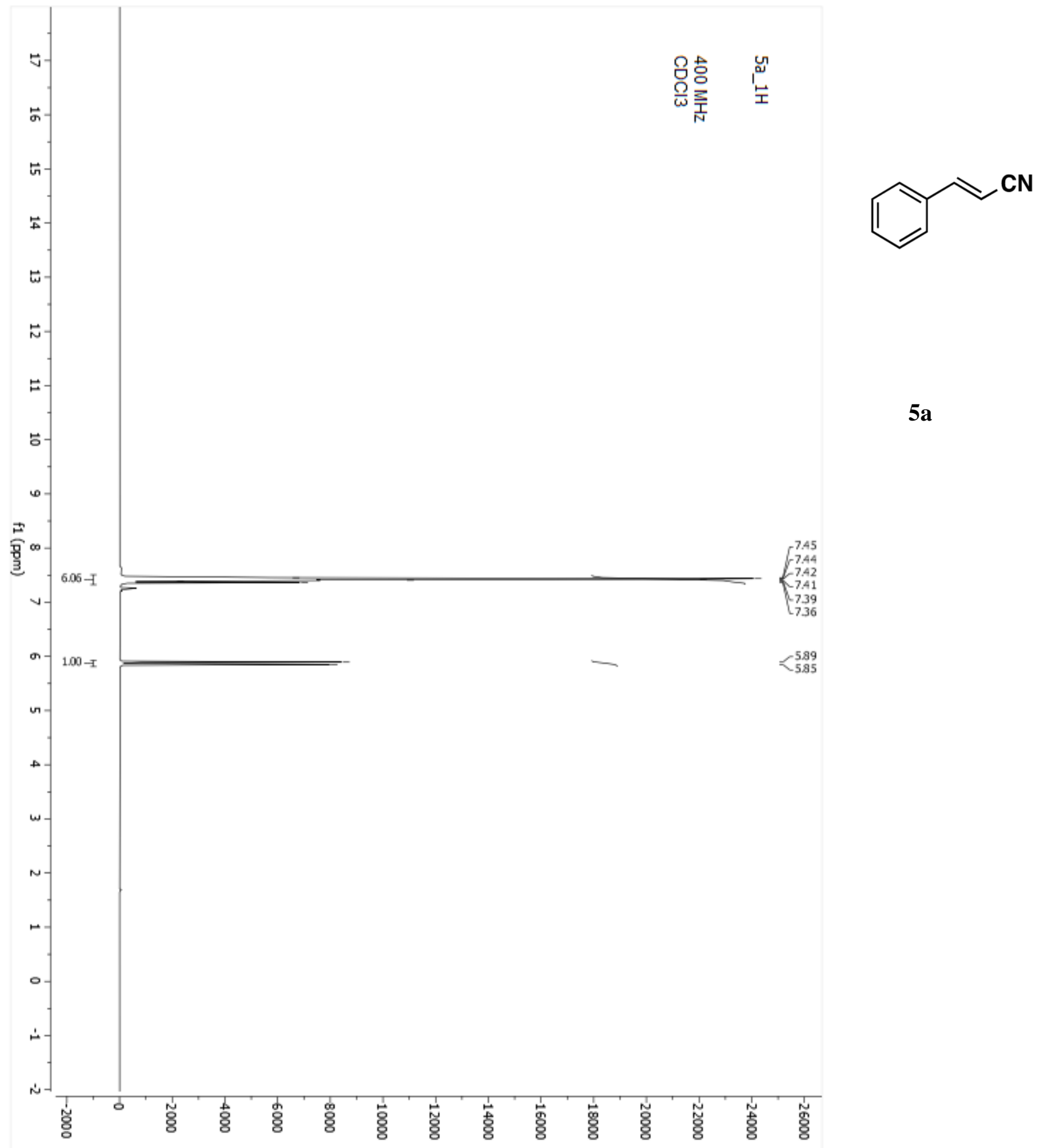

S7. ${ }^{1} \mathrm{H}$ NMR Spectrum of $\mathbf{5 a}$. 


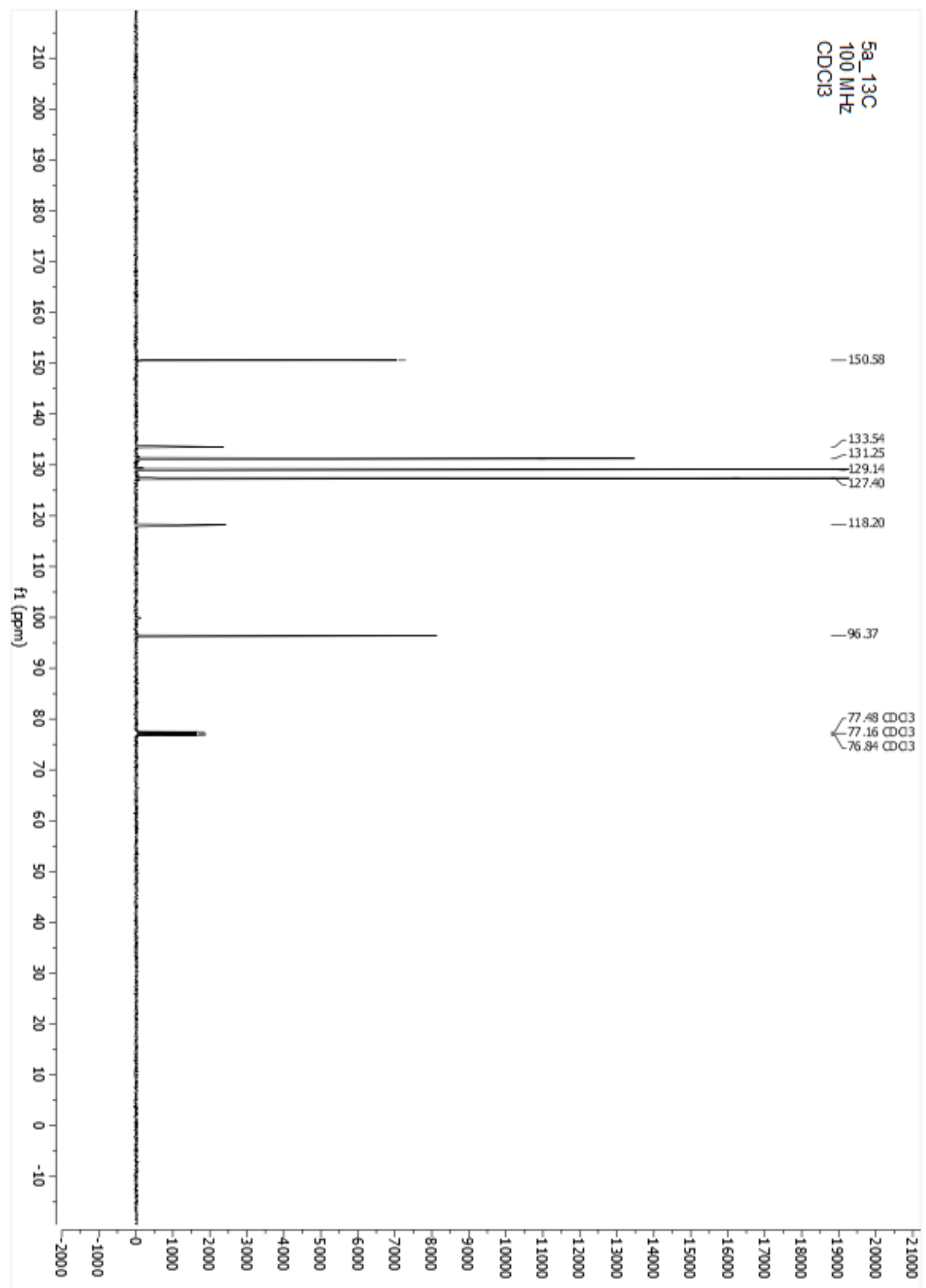

S8. ${ }^{13} \mathrm{C}$ NMR Spectrum of $\mathbf{5 a}$. 


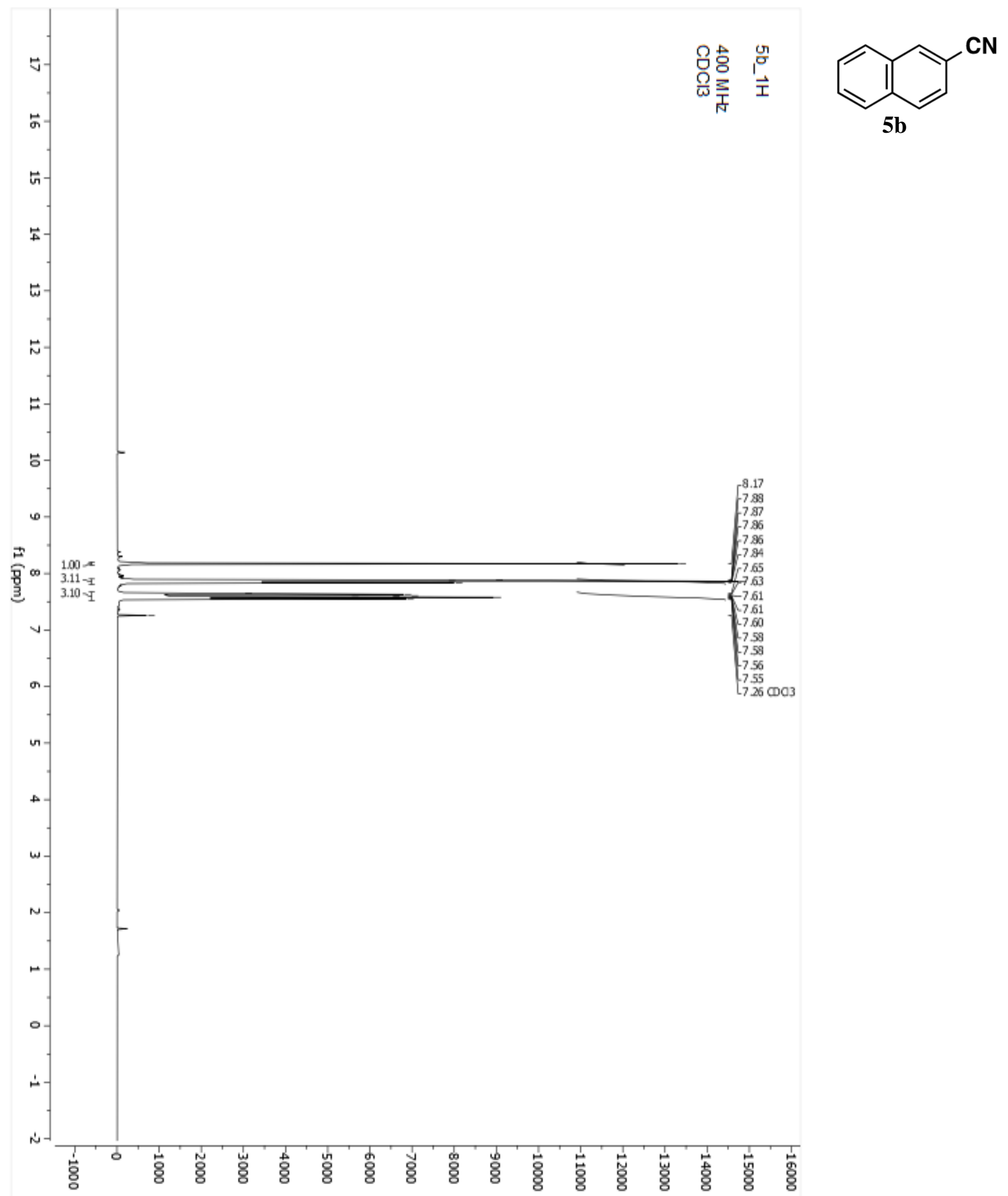

S9. ${ }^{1} \mathrm{H}$ NMR Spectrum of $\mathbf{5 b}$. 

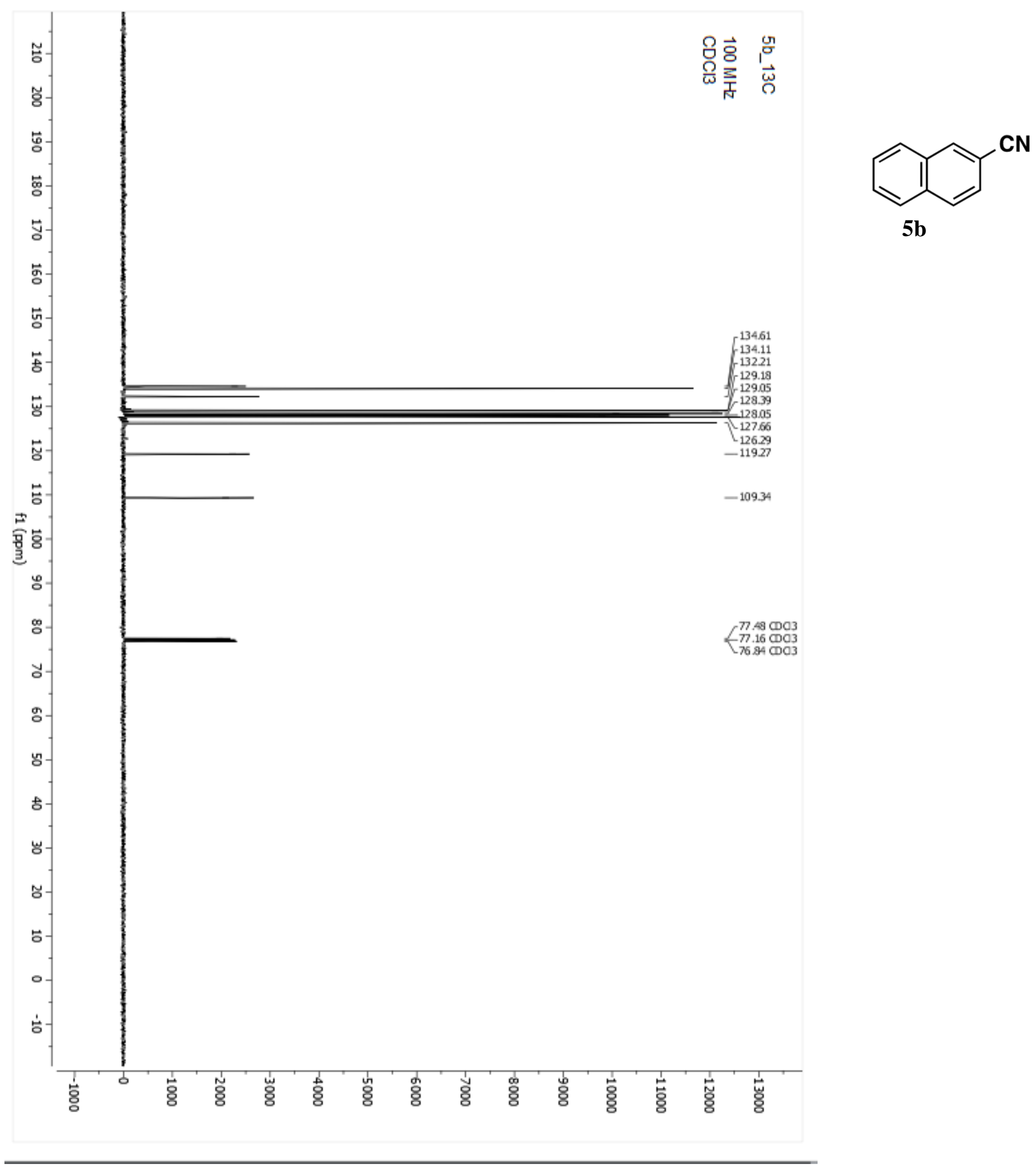

S10. ${ }^{13} \mathrm{C}$ NMR Spectrum of $\mathbf{5 b}$. 


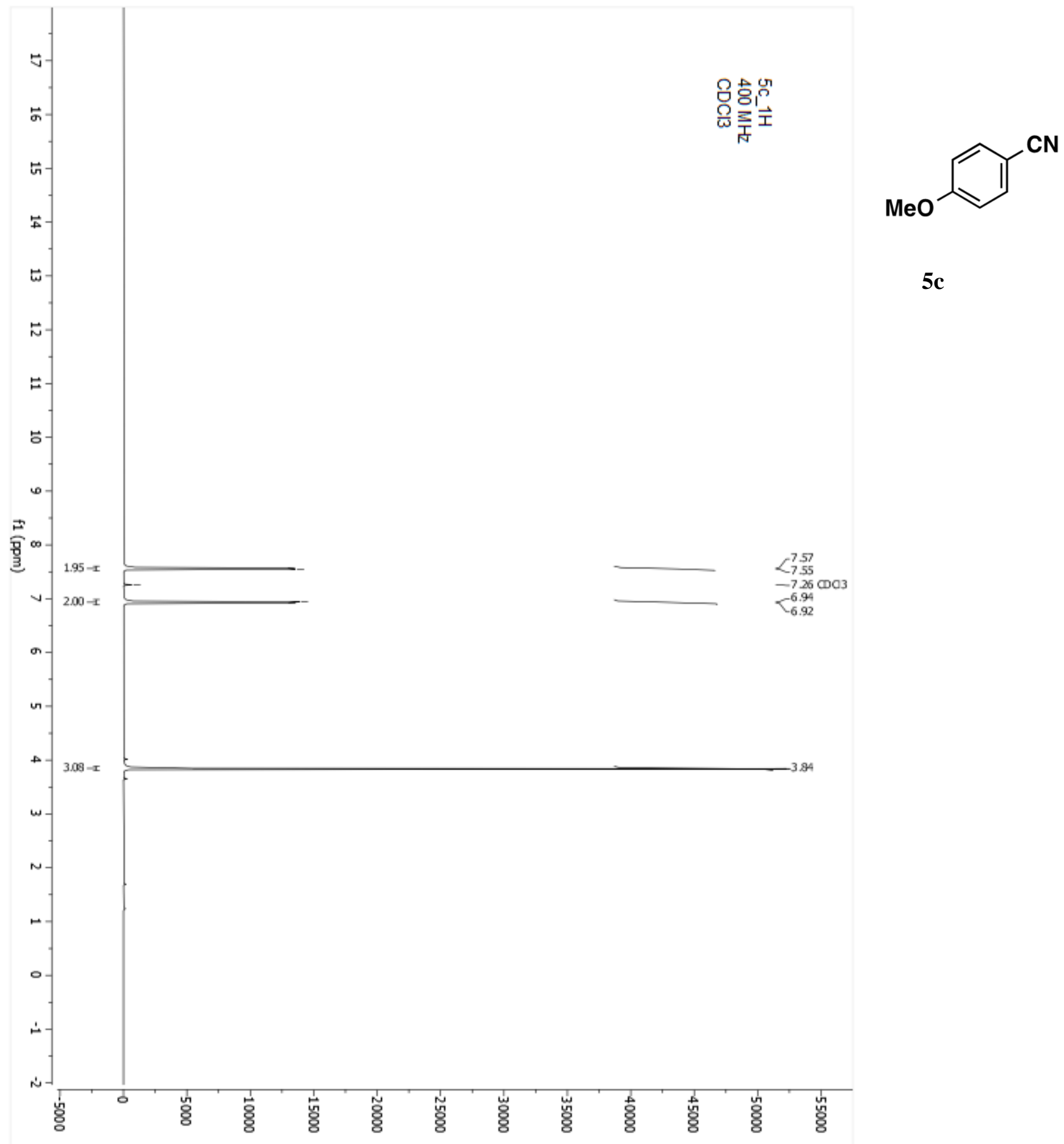

S11. ${ }^{1} \mathrm{H}$ NMR Spectrum of $\mathbf{5 c}$. 


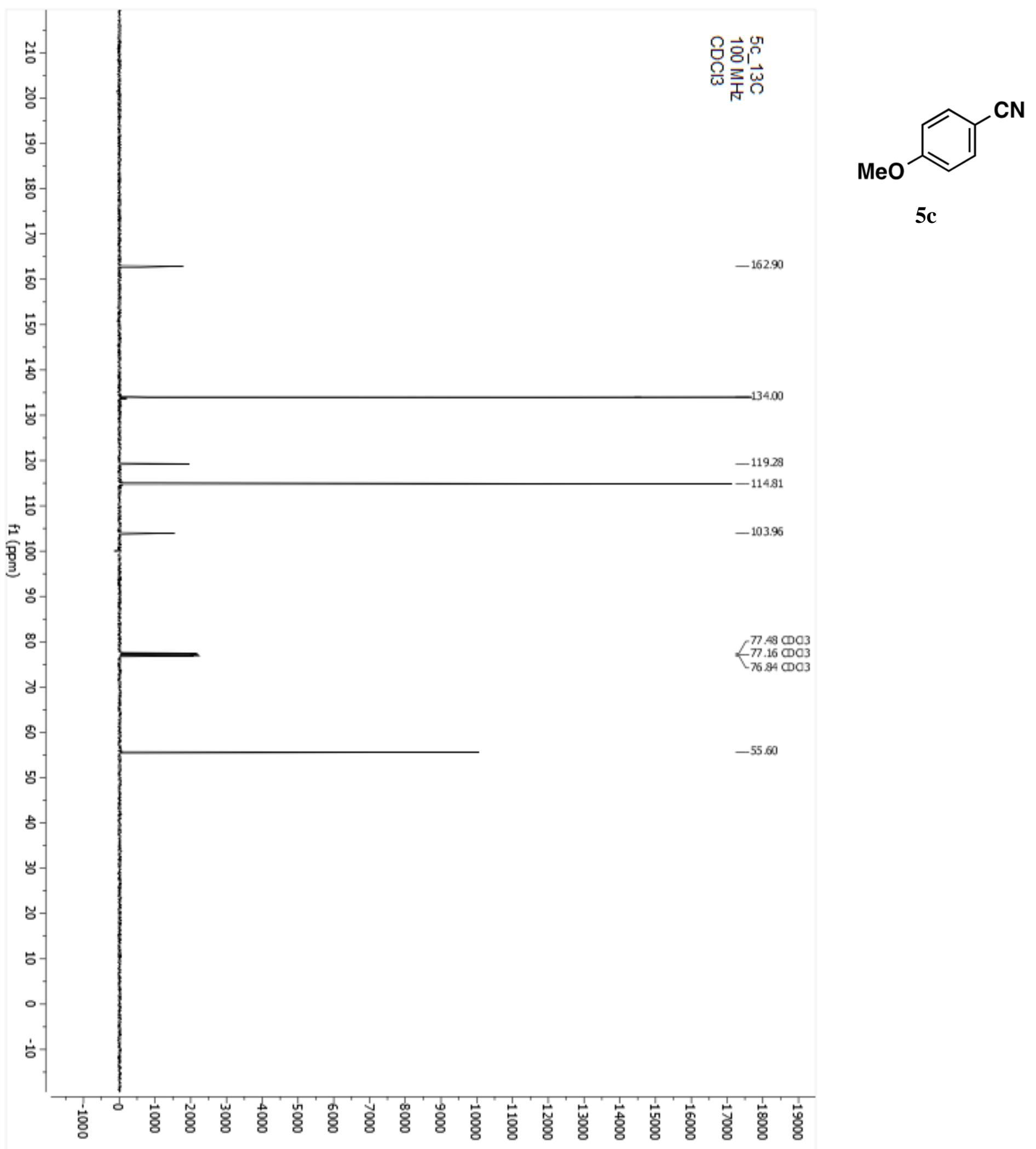

S12. ${ }^{13} \mathrm{C}$ NMR Spectrum of $\mathbf{5 c}$. 


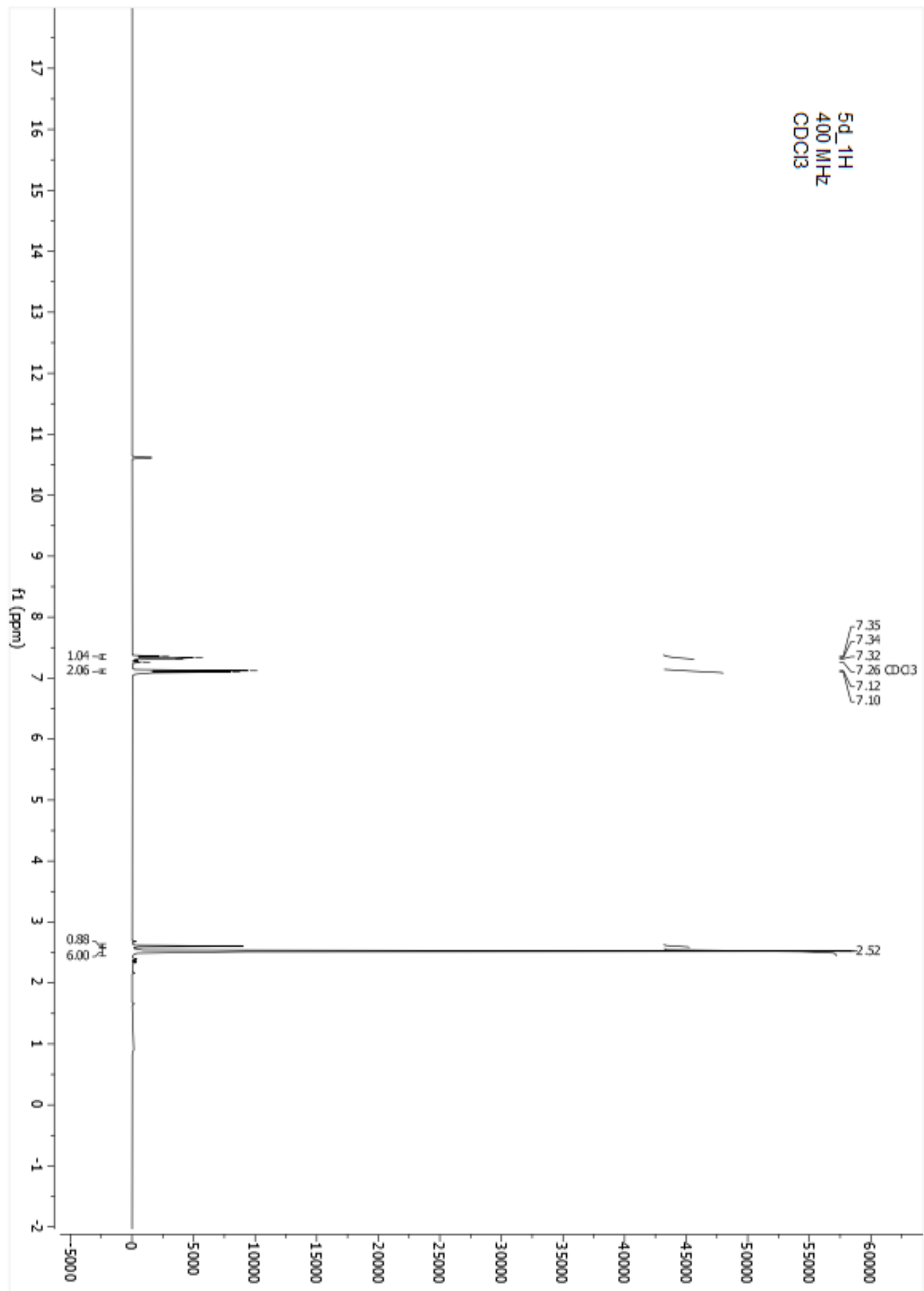

$5 d$

S13. ${ }^{1}$ H NMR Spectrum of $\mathbf{5 d}$. 


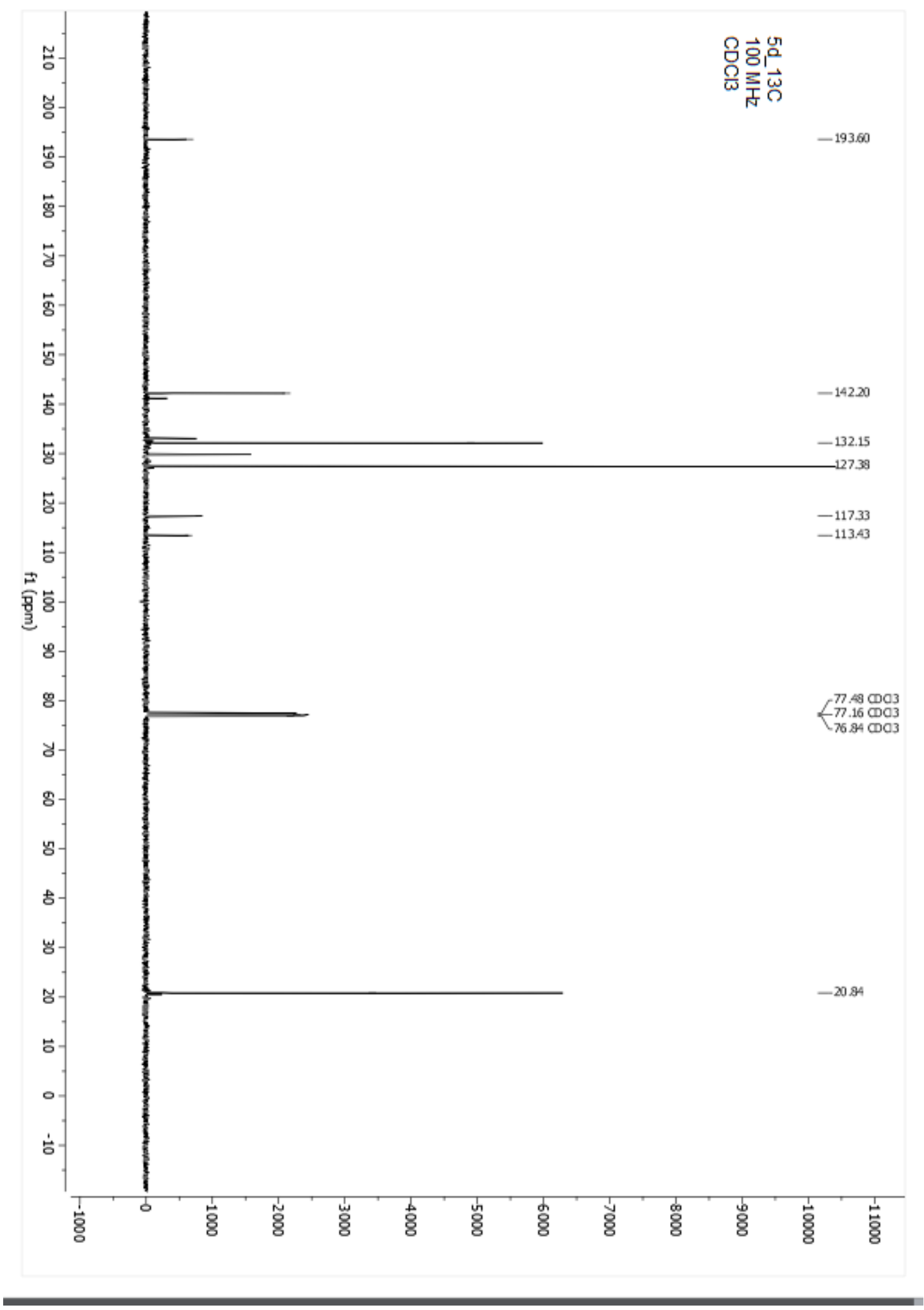

$5 d$

S14. ${ }^{13} \mathrm{C}$ NMR Spectrum of $\mathbf{5 d}$. 


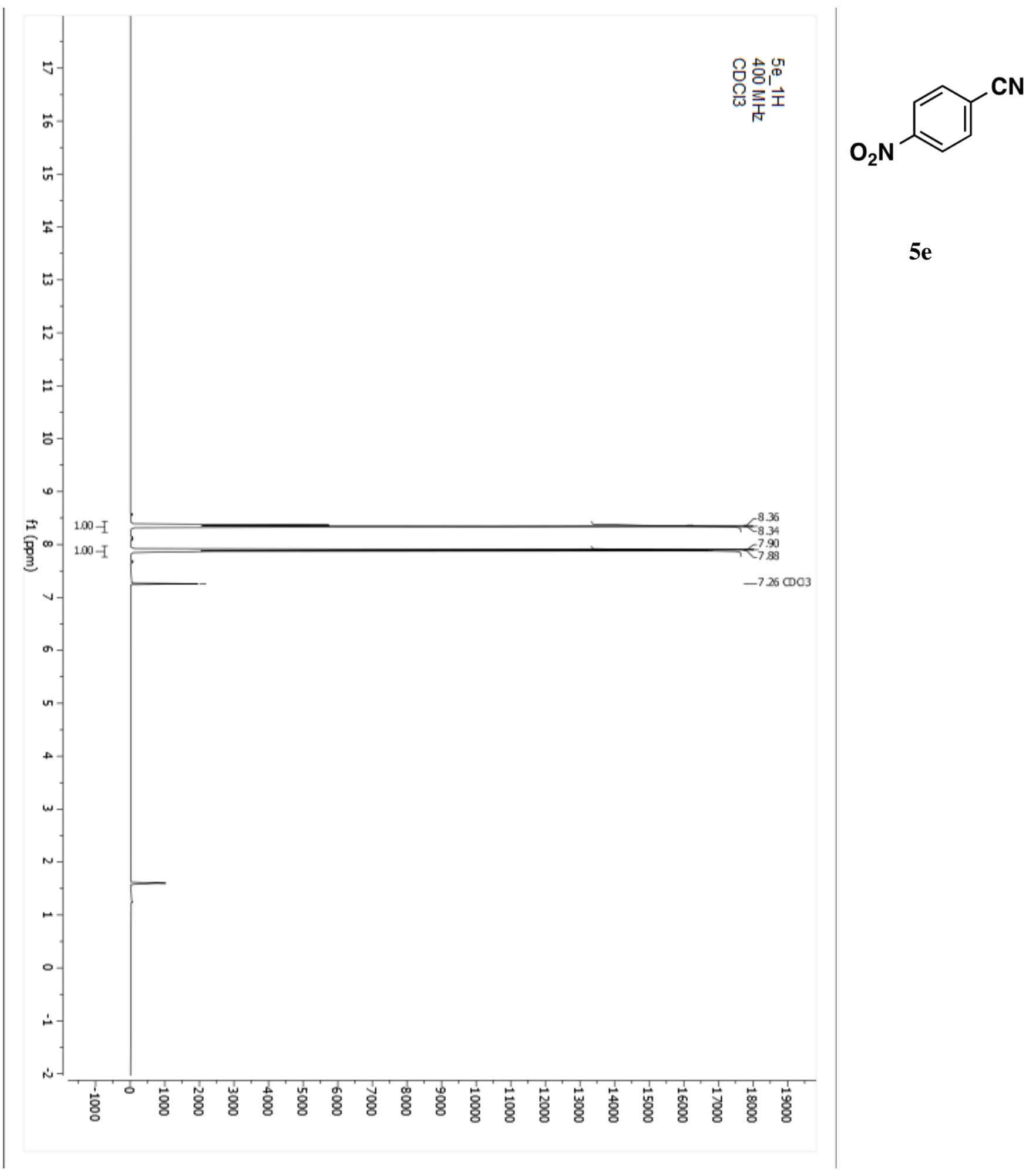

S15. ${ }^{1} \mathrm{H}$ NMR Spectrum of $\mathbf{5 e}$. 


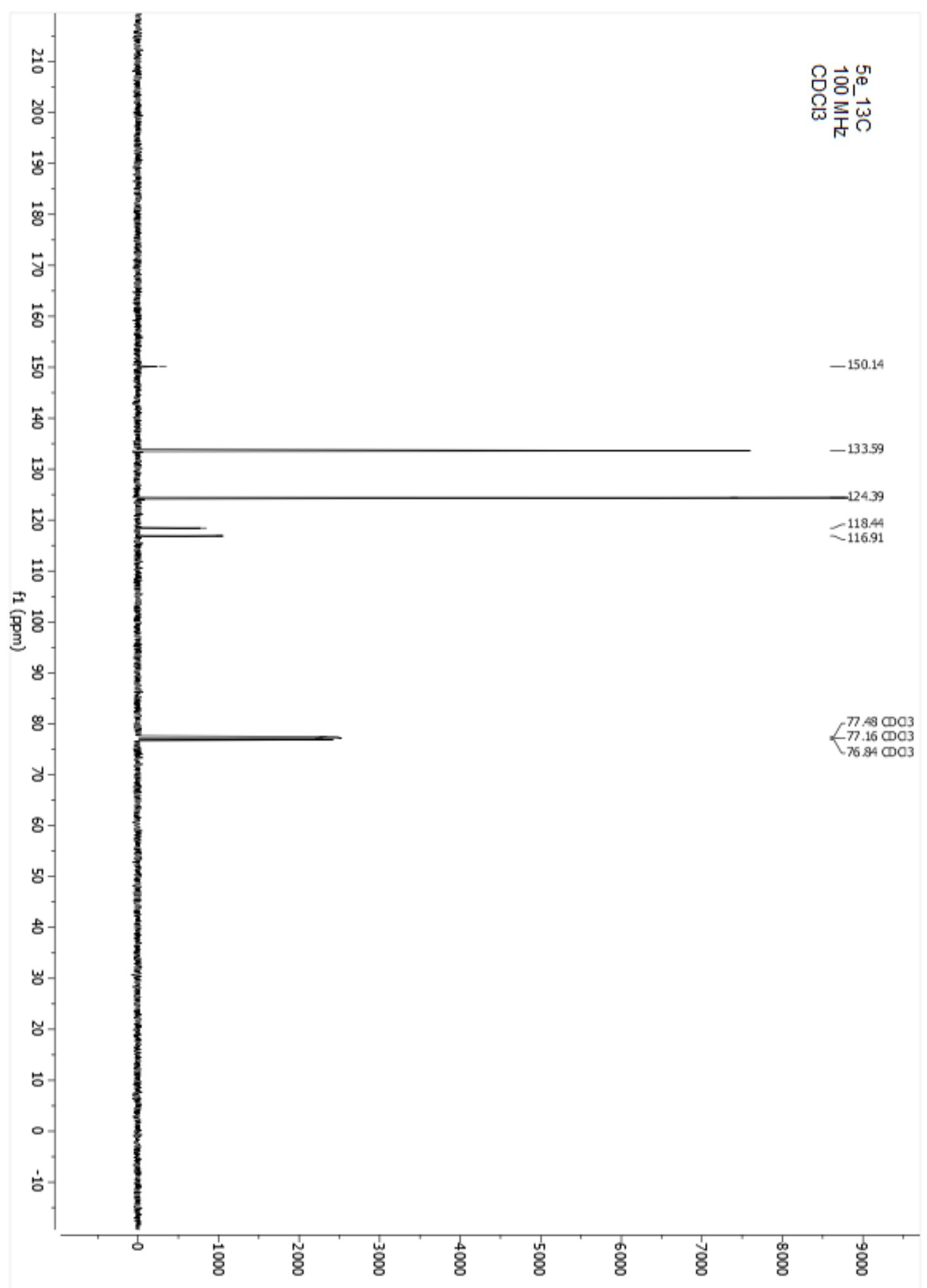

$5 e$

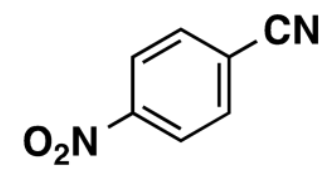




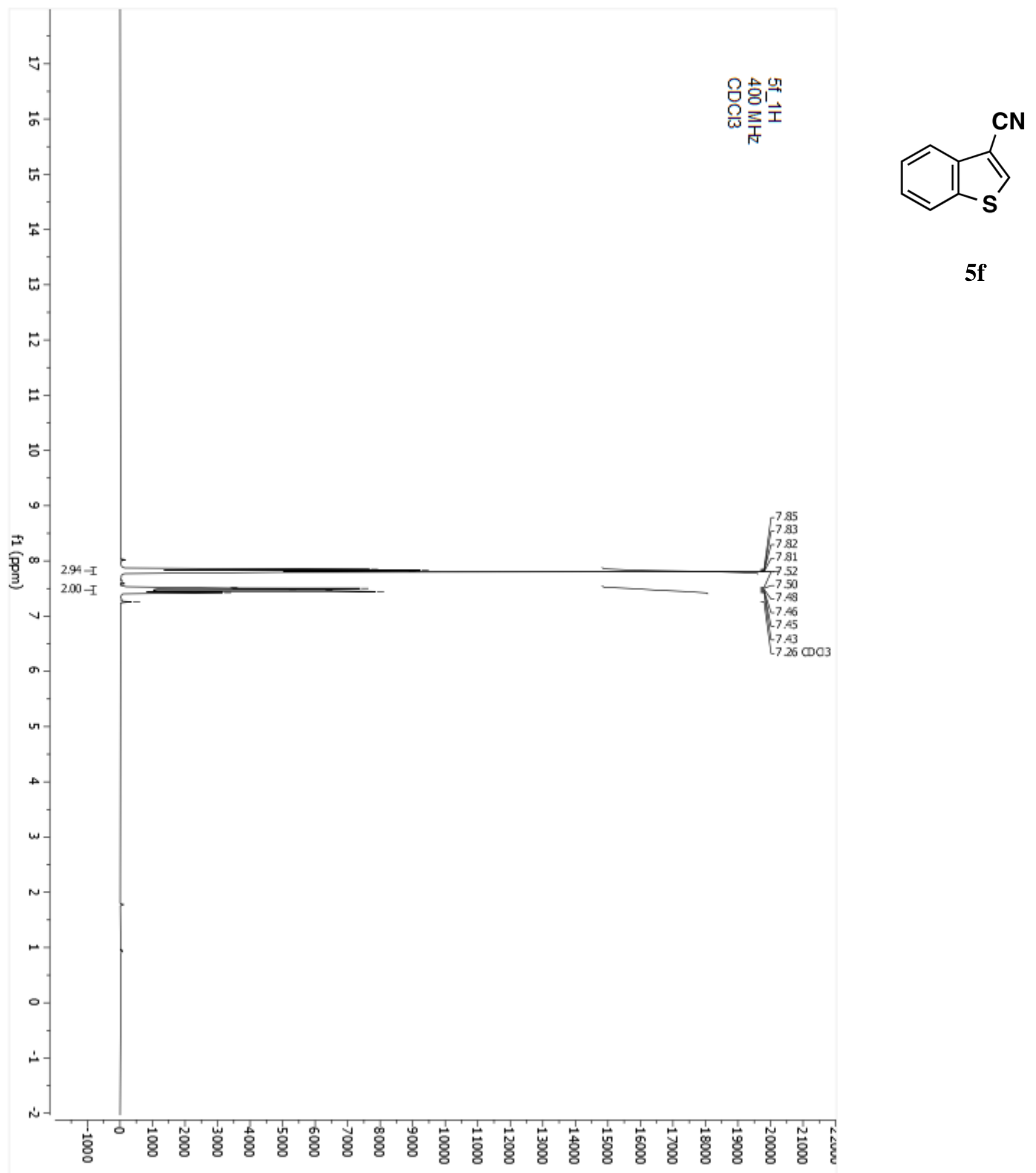

S17. ${ }^{1}$ H NMR Spectrum of $\mathbf{5 f}$. 


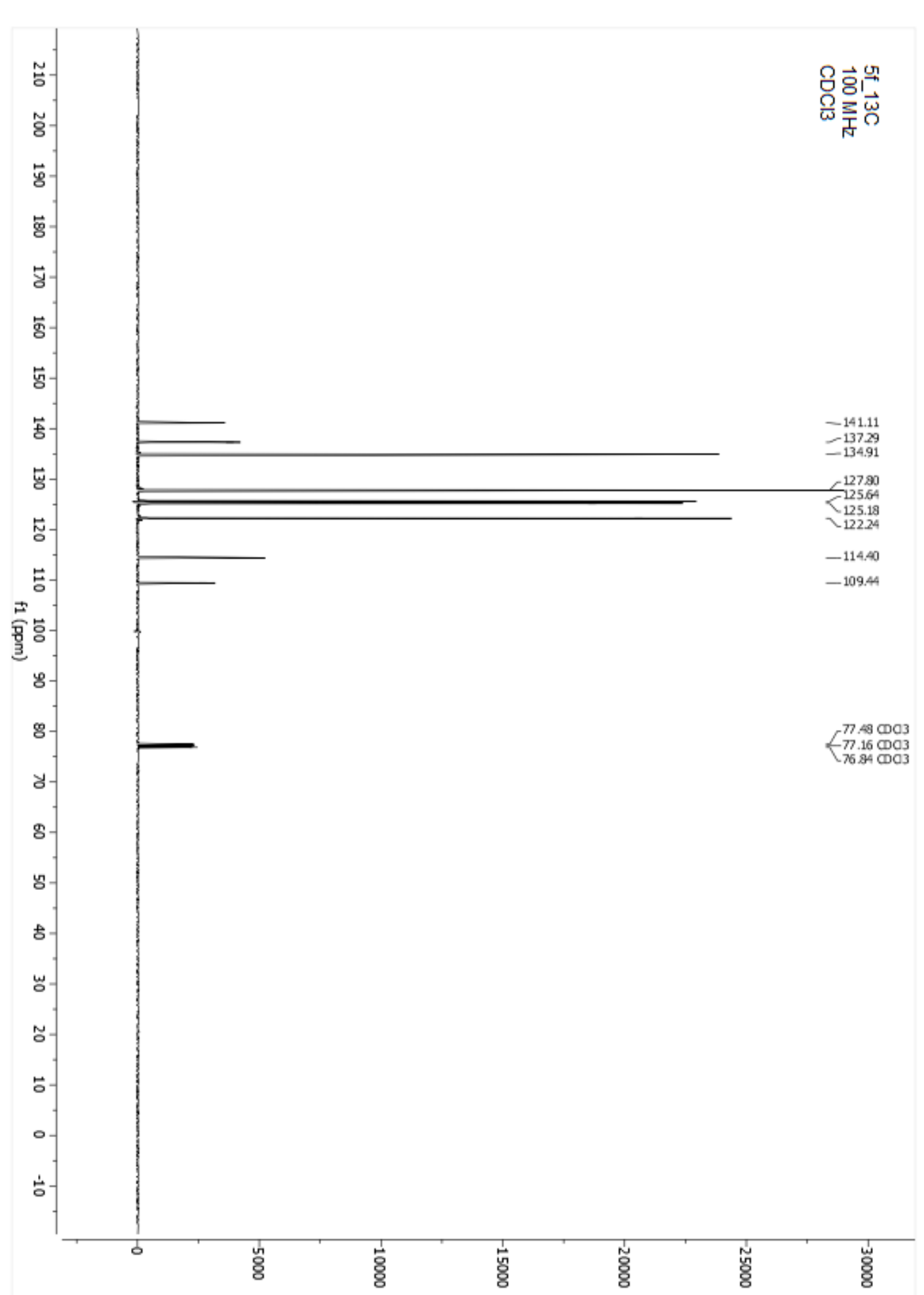

S18. ${ }^{13} \mathrm{C}$ NMR Spectrum of $\mathbf{5 f}$. 


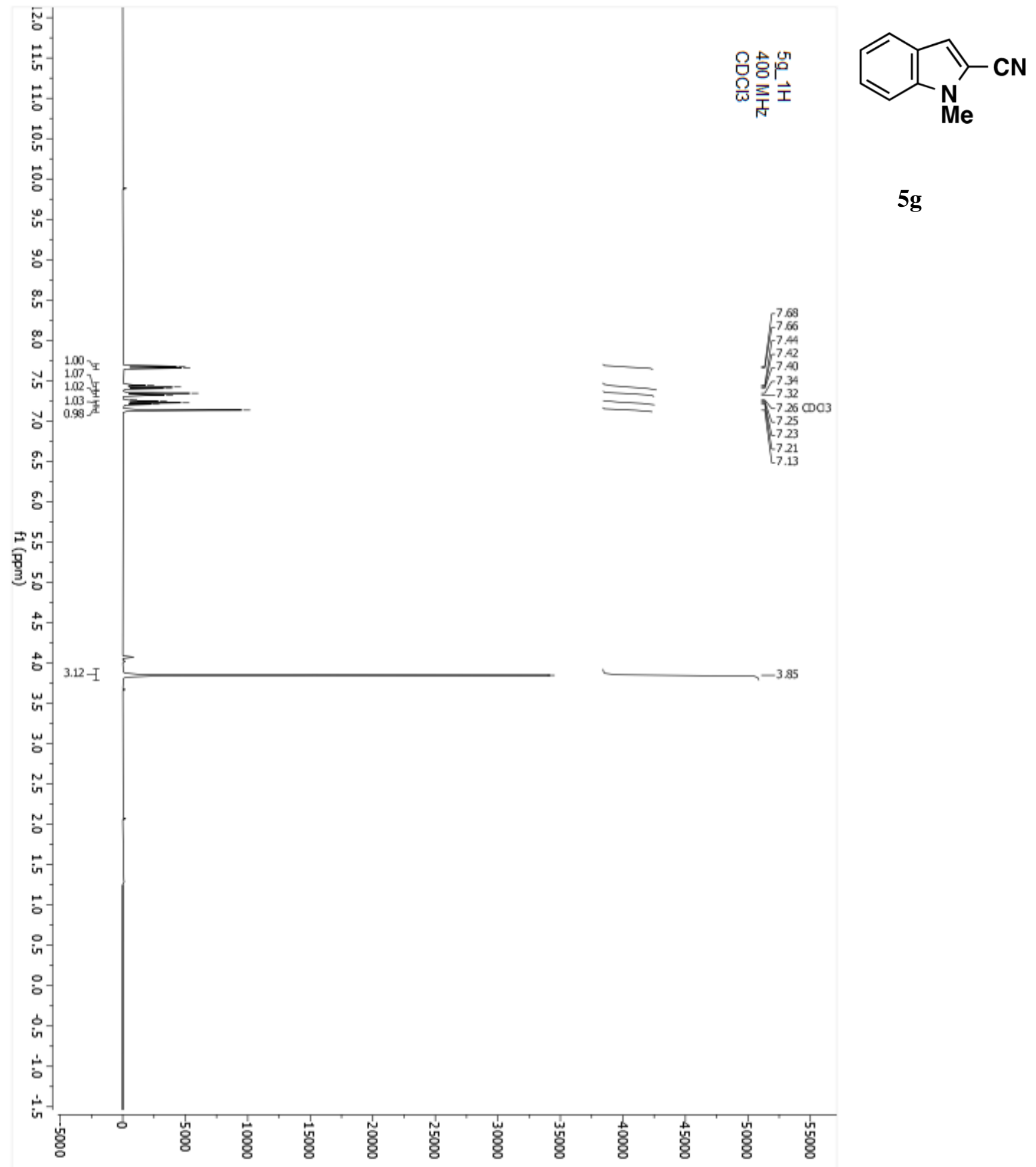

S19. ${ }^{1} \mathrm{H}$ NMR Spectrum of $\mathbf{5 g}$. 


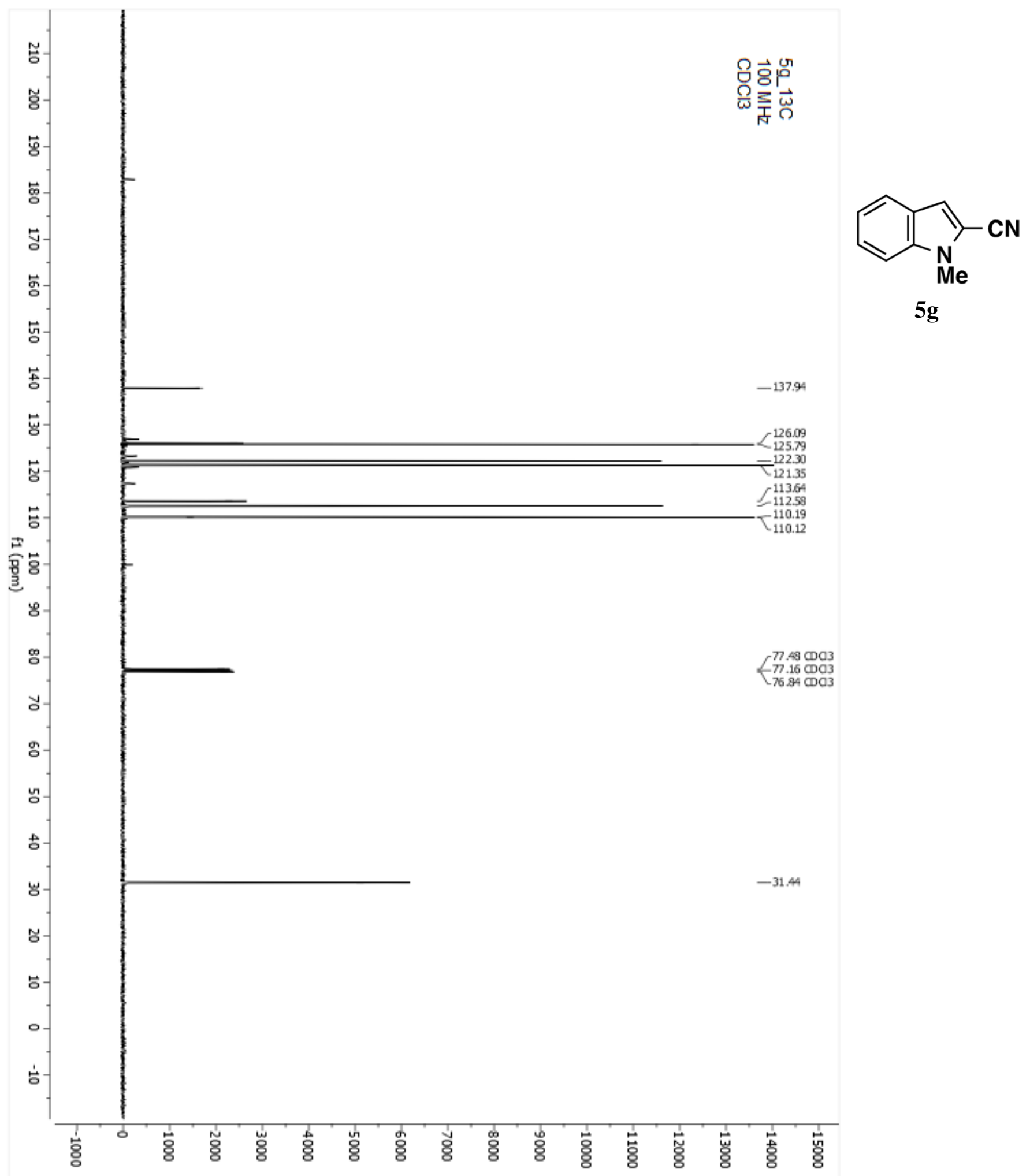

S20. ${ }^{13} \mathrm{C}$ NMR Spectrum of $\mathbf{5 g}$. 


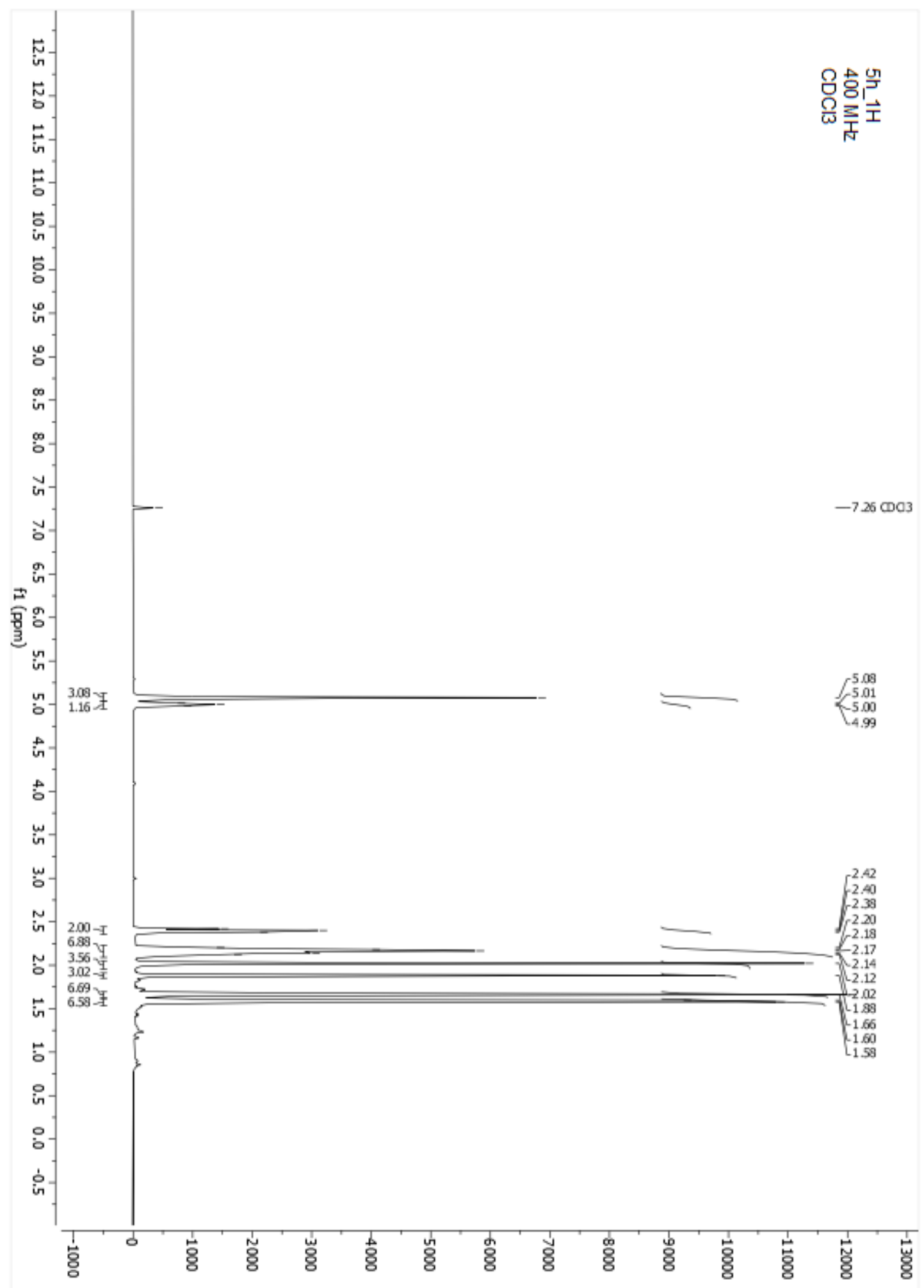

$5 h$

S21. ${ }^{1}$ H NMR Spectrum of $\mathbf{5 h}$. 


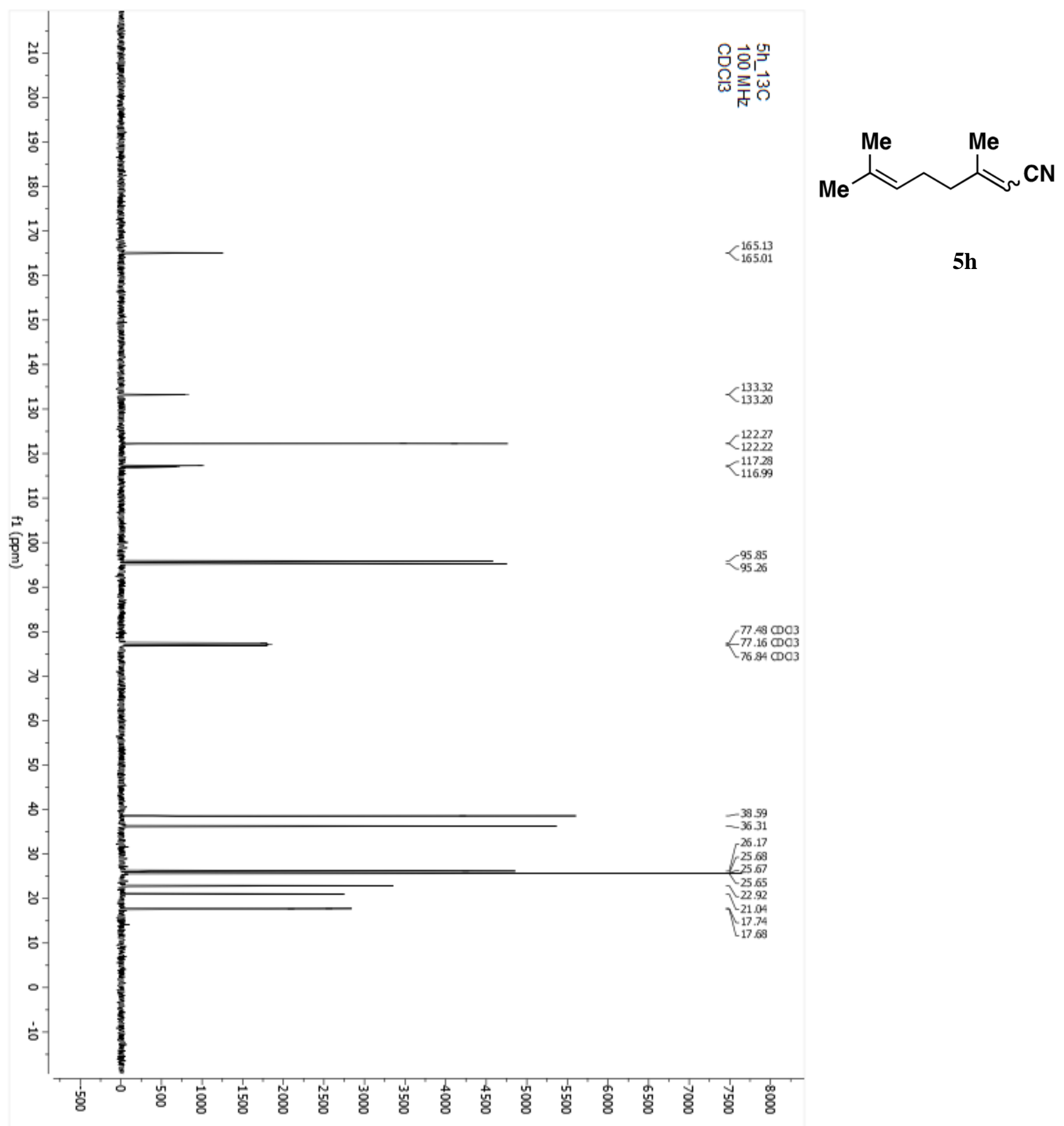

S22. ${ }^{13} \mathrm{C}$ NMR Spectrum of $\mathbf{5 h}$. 

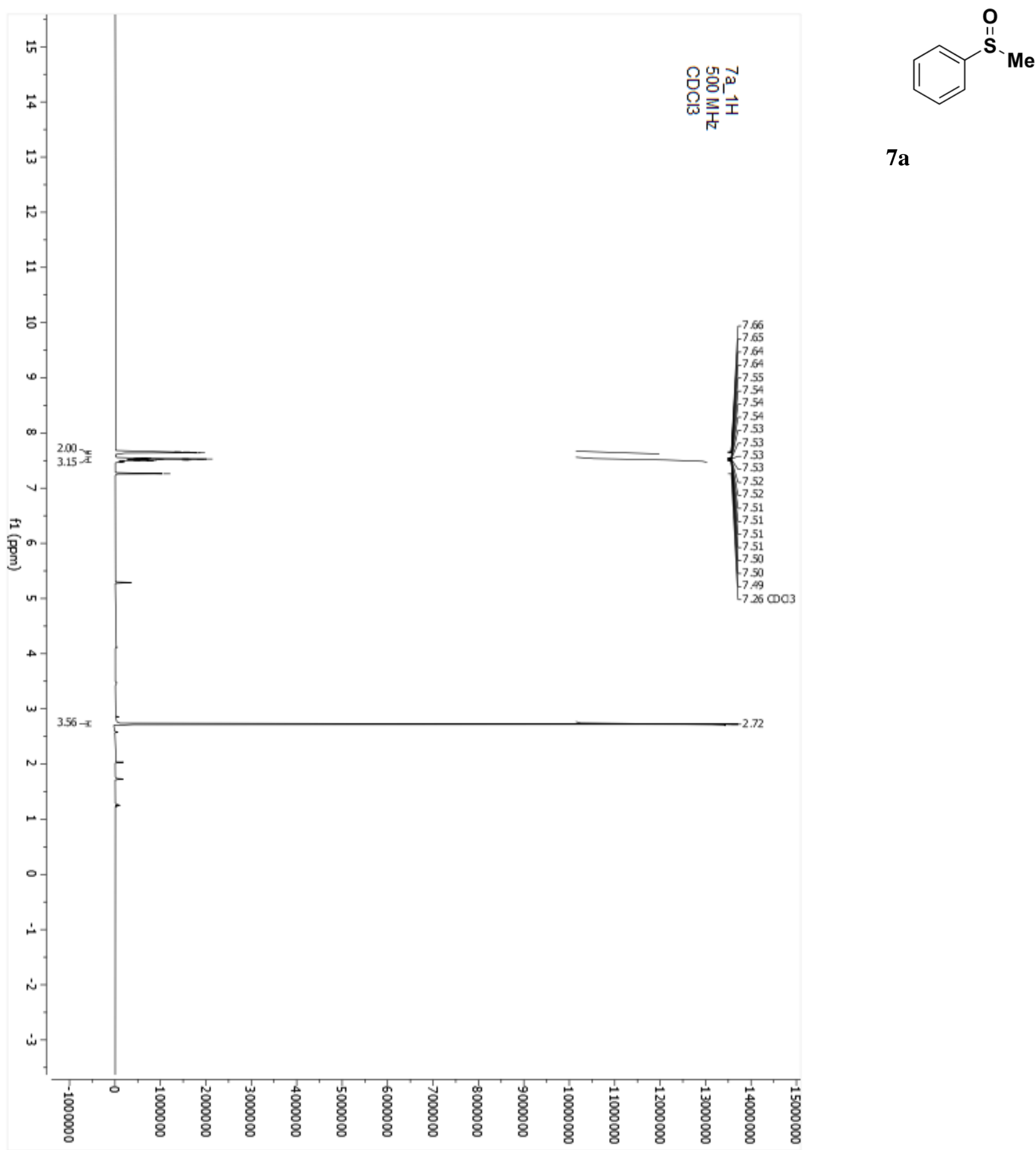

$7 a$

S23. ${ }^{1} \mathrm{H}$ NMR Spectrum of $\mathbf{7 a}$. 


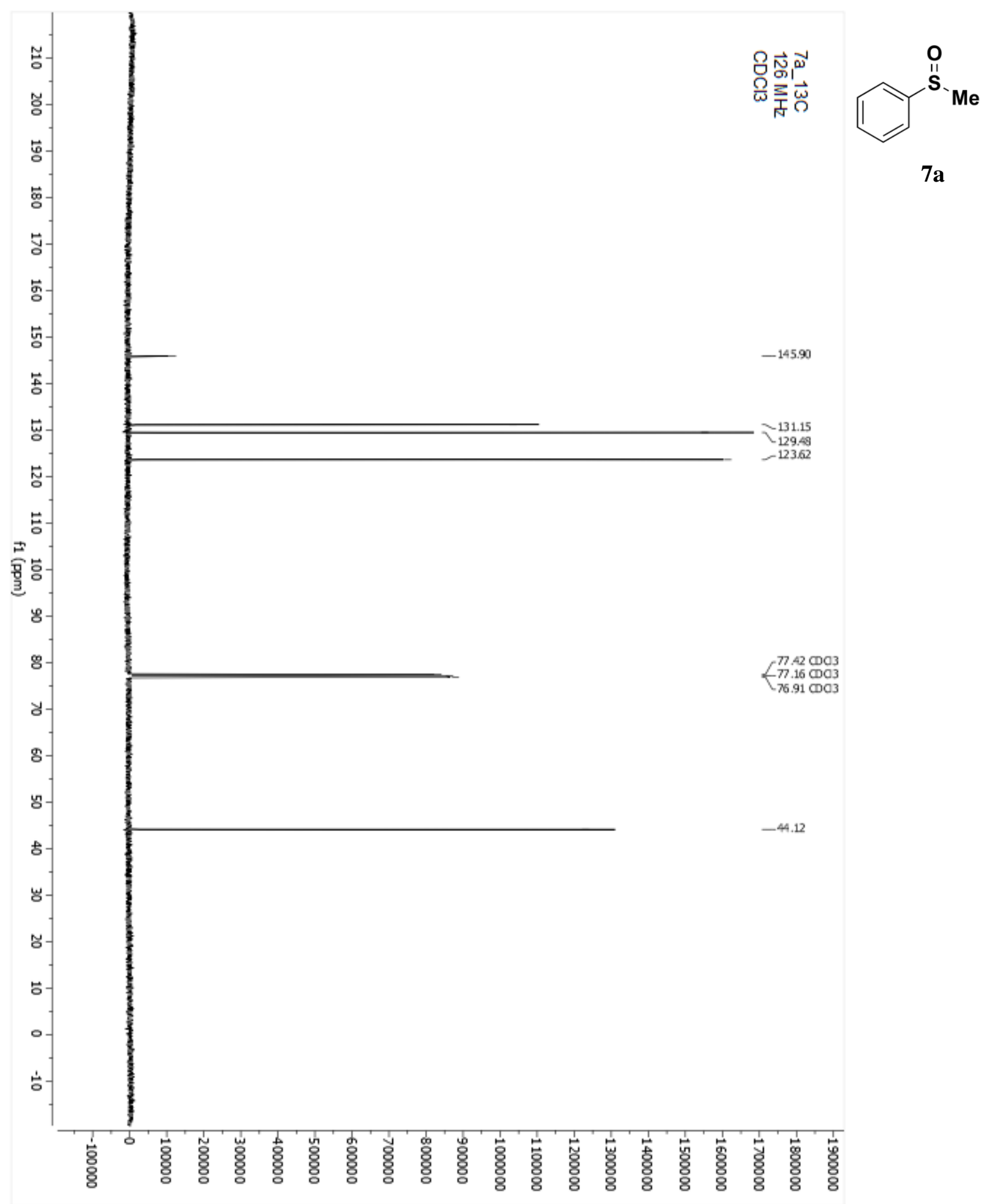

S24. ${ }^{13} \mathrm{C}$ NMR Spectrum of 7a. 


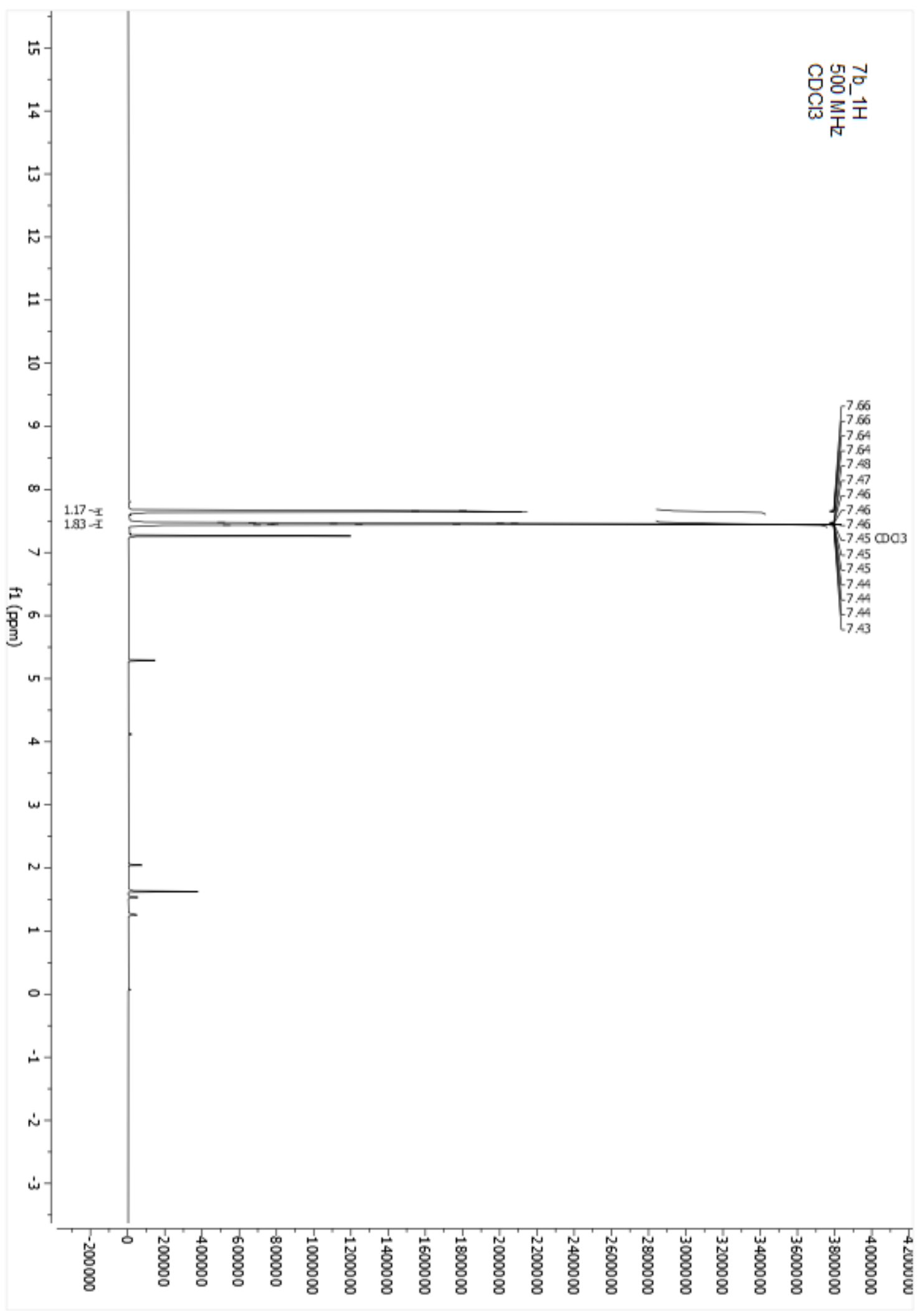

$7 b$

S25. ${ }^{1} \mathrm{H}$ NMR Spectrum of $\mathbf{7 b}$. 


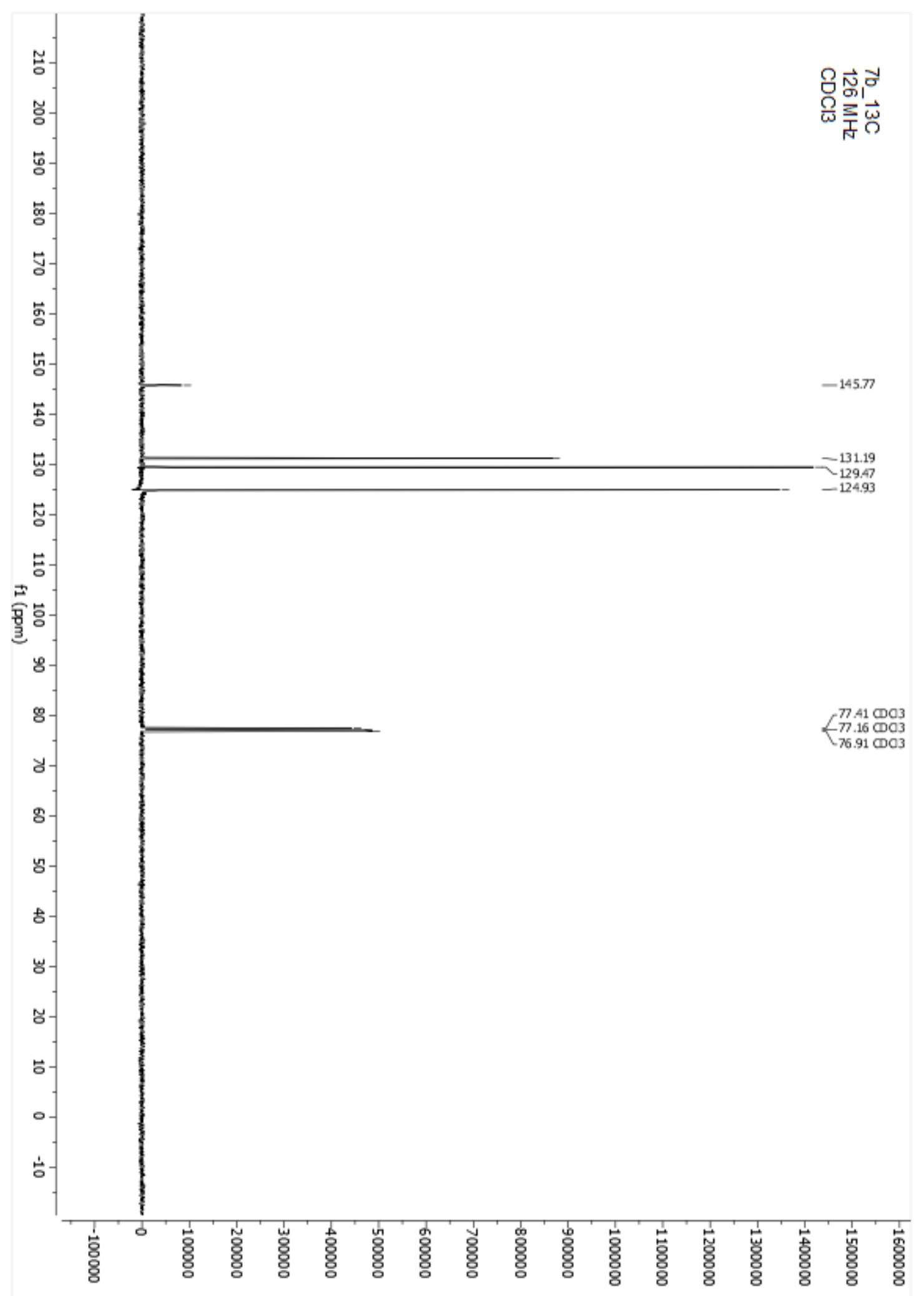

S26. ${ }^{13} \mathrm{C}$ NMR Spectrum of 7b 

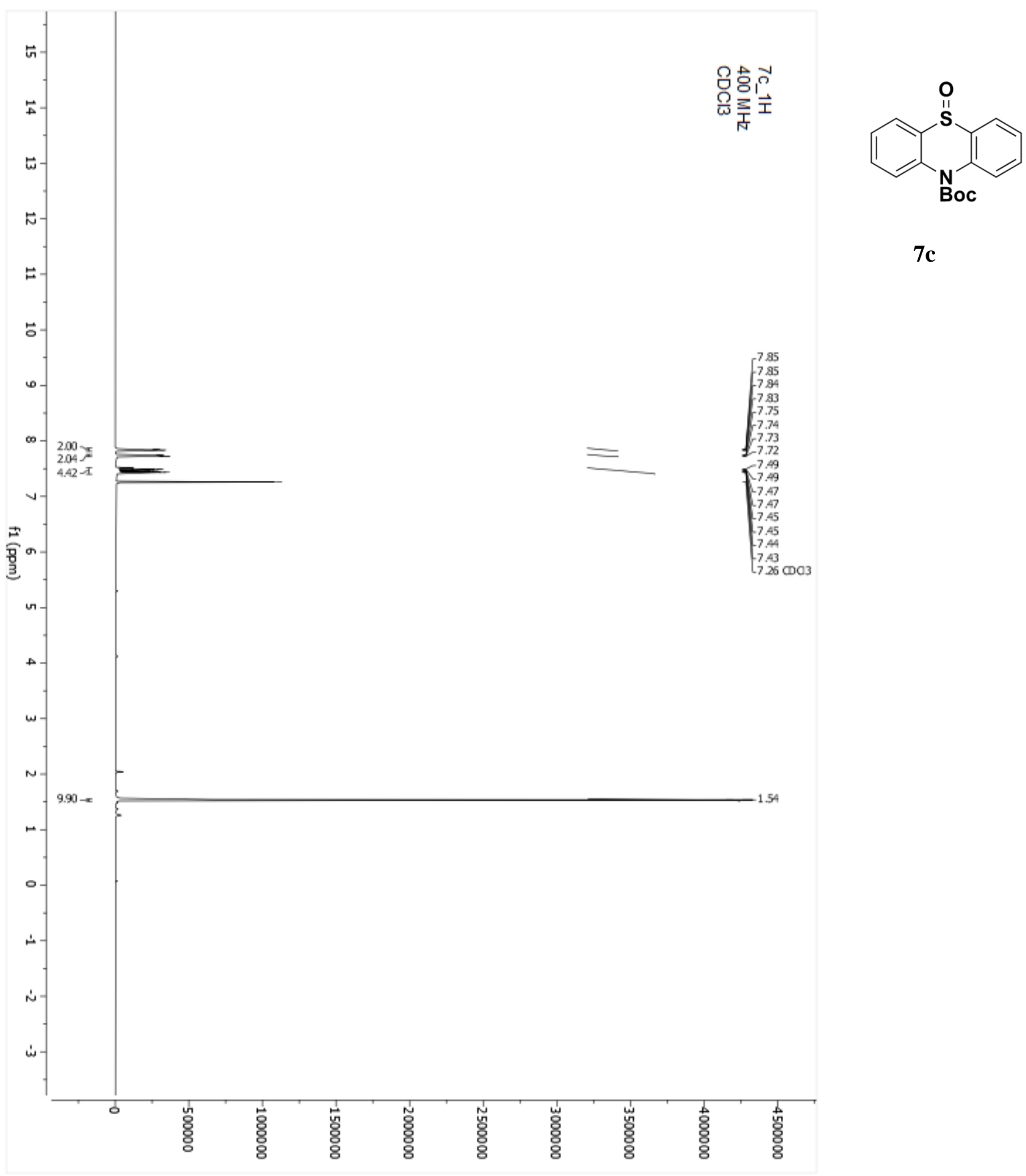

7c

S27. ${ }^{1} \mathrm{H}$ NMR Spectrum of 7c. 


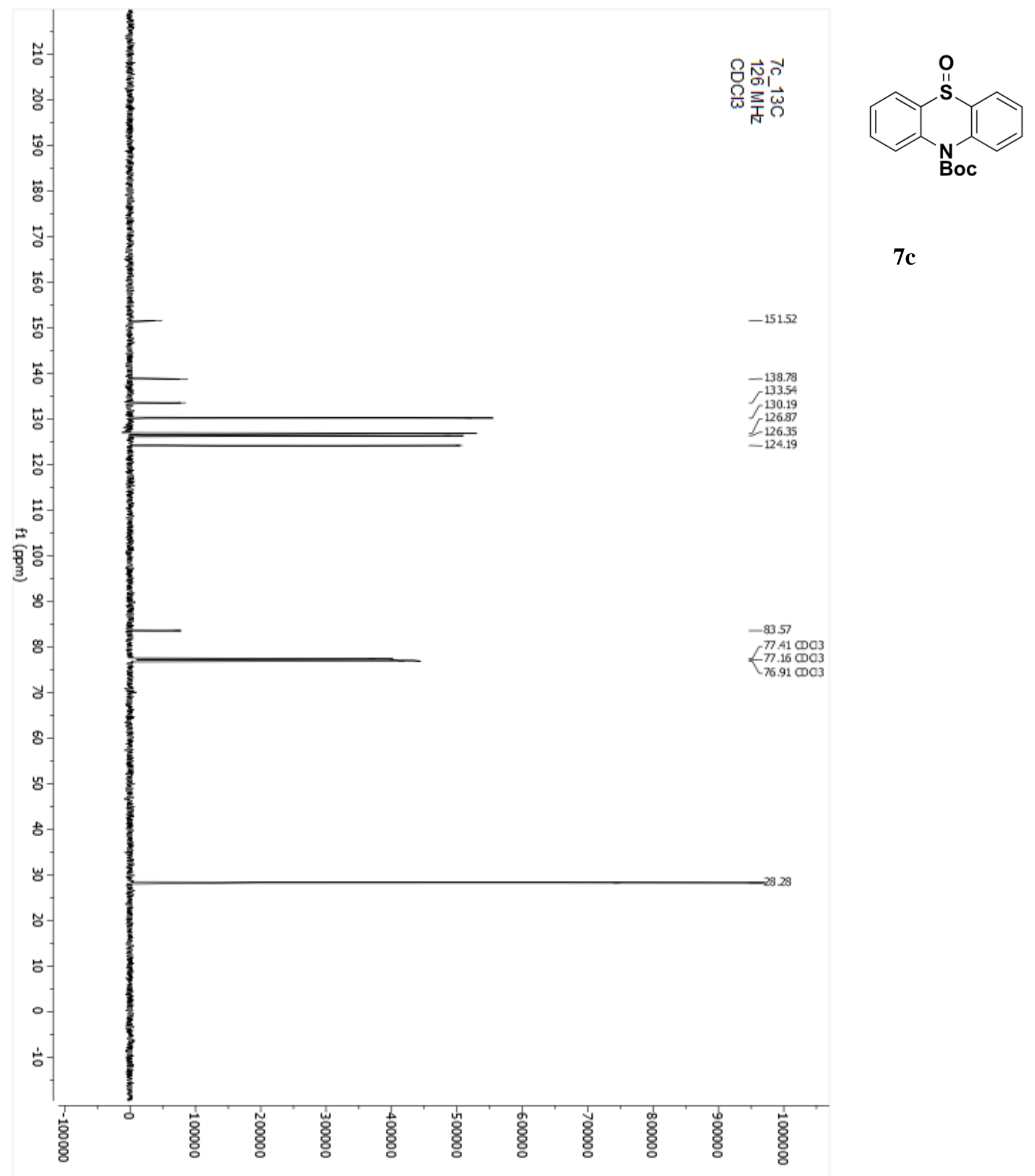

S28. ${ }^{13} \mathrm{C}$ NMR Spectrum of 7c. 


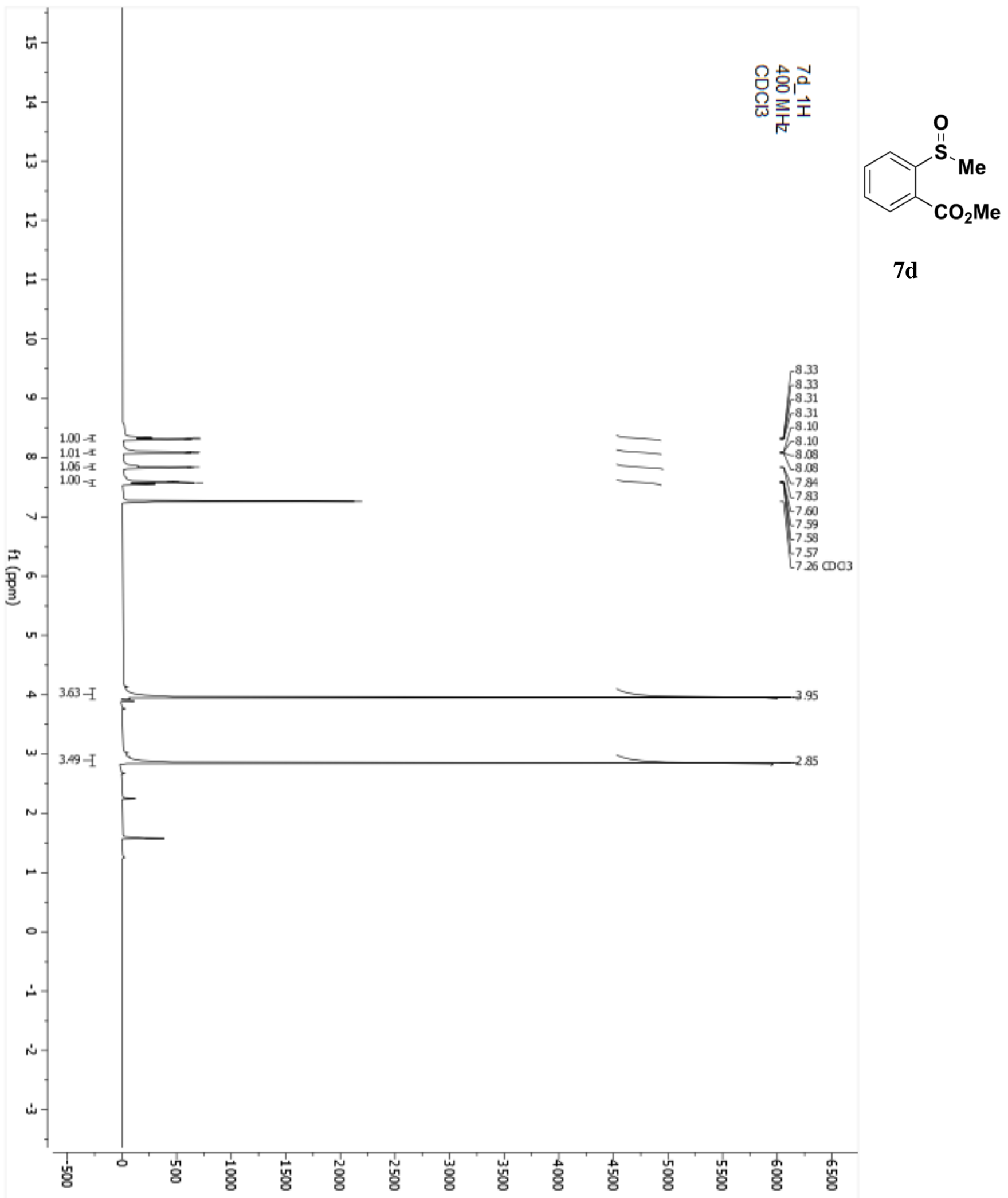

S29. ${ }^{1} \mathrm{H}$ NMR Spectrum of 7d. 


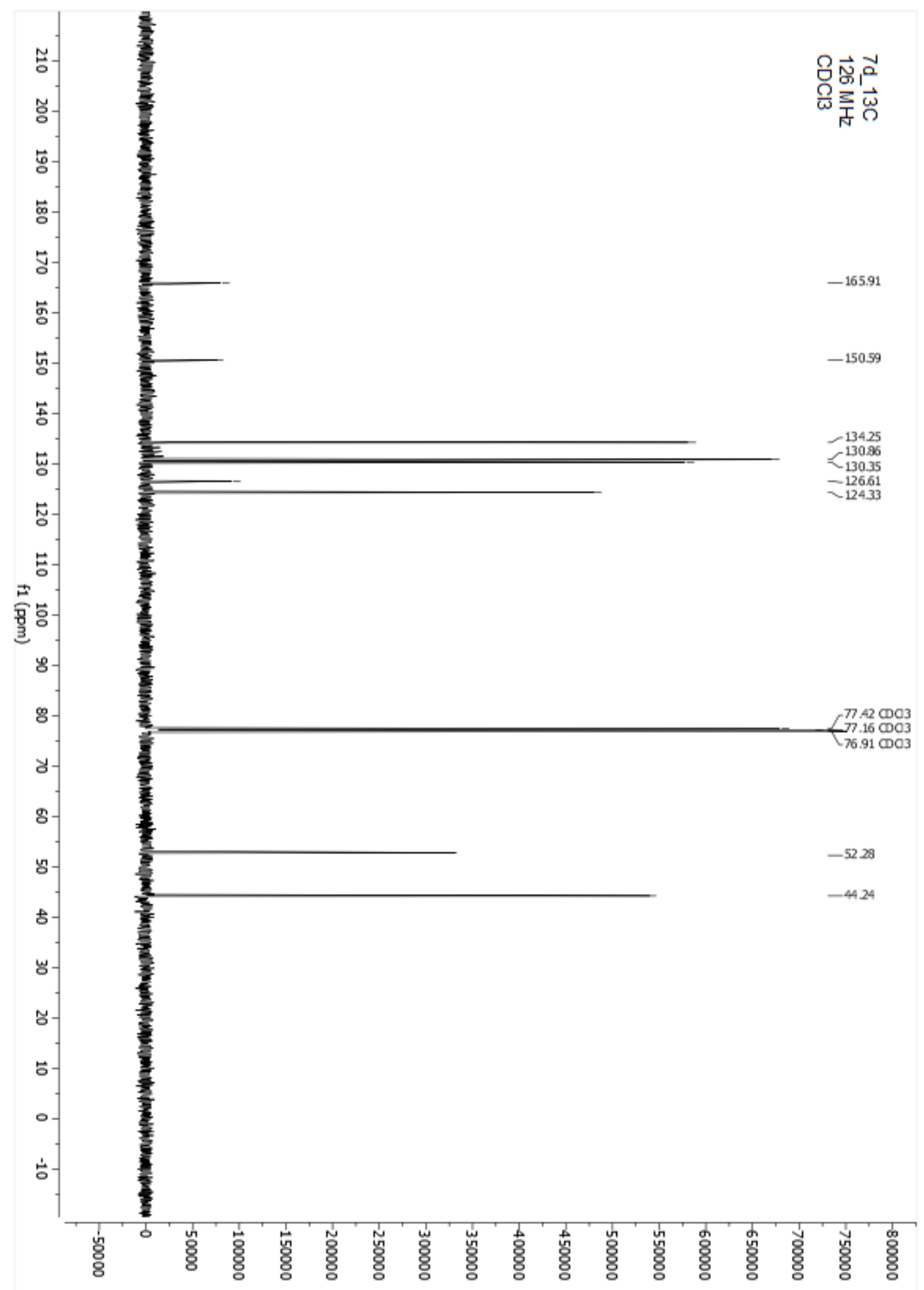

7d

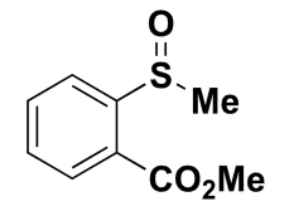

